\title{
A Theoretical Model for Hydraulic Fracturing through Two Symmetric Radial Perforations Emanating from A Borehole
}

\author{
Shibin Tang $\mathbb{D}^{1},{ }^{1}$ Zhuo Dong, ${ }^{1}$ Dong Duan, ${ }^{2}$ and Yingchun Li $\mathbb{D}^{1}$ \\ ${ }^{1}$ School of Civil Engineering, Dalian University of Technology, Dalian 116024, China \\ ${ }^{2}$ College of Mining Engineering, Taiyuan University of Technology, Taiyuan 030024, China \\ Correspondence should be addressed to Shibin Tang; tang_shibin@dlut.edu.cn
}

Received 15 January 2019; Revised 28 April 2019; Accepted 13 May 2019; Published 9 June 2019

Academic Editor: Antonio Caggiano

Copyright (c) 2019 Shibin Tang et al. This is an open access article distributed under the Creative Commons Attribution License, which permits unrestricted use, distribution, and reproduction in any medium, provided the original work is properly cited.

The production enhancement of oil, gas, or geothermal reservoirs through hydraulic fracturing requires an in-depth study on the fracture initiation and propagation from the borehole. According to the linear elastic fracture mechanics, a theoretical model is developed to calculate the stress intensity factors of two symmetric radial cracks emanating from a pressurized borehole. The maximum tangential stress criterion under the mix-mode condition is developed to investigate the hydraulic fracture initiation. The critical water pressure and critical initiation angle predicted by the theoretical model match closely the experimental results reported in the literature. The influence of the stress anisotropy coefficient, the perforation angle and length, the borehole radius, the ratio between the water pressures in the fracture and the borehole, and Biot's coefficient are investigated. Moreover, the effects of the injected high water pressure (i.e., larger than the critical water pressure) on the fracture initiation angle are studied to further understand the characteristics of hydraulic fracture initiation. The results indicate that the perforation angle and length, the borehole radius, and the stress anisotropy coefficient have a relatively strong influence on the critical water pressure and critical initiation angle. During high-pressure water injection, the fracture initiation angle decreases as the ratio between the water pressure in the fracture and the borehole and Biot's ratio increase. The theoretical model provides a comprehensive understanding of the fracture twist, the mixed-mode fracture propagation feature, and the hydraulic fracturing optimization.

\section{Introduction}

Hydraulic fracturing has been widely used in the petroleum industry since the 1930s for enhancing production from oil and gas wells [1]. During hydraulic fracturing, high water pressure is pumped into boreholes to break down lowpermeability oil and gas that flow into the well from the reservoirs. One of the most important tasks in hydraulic fracturing design is to predict the fracturing path and the injected water pressure. Generally, hydraulic fractures open in the direction of least resistance (in a plane perpendicular to the minimum horizontal stress) [2]. An ideal horizontal well is usually designed parallel to the orientation of the minimum in situ stress so that the fracture plane induced by hydraulic fracturing operation is perpendicular to the axis of the borehole. However, in practice, the real trajectories of the horizontal wells frequently deviate from the designed direction due to the limitations of controlling technology in drilling. Therefore, the crack growth direction will change under different horizontal differential stress (the difference between the maximum and minimum horizontal stresses) [2]. The orientation of the newly formed fractures is critical to the hydraulic fracturing operations and well production. The curved shape of a fracture strongly affects fluid flow because of additional frictions and changing fluid rheology, especially for fracturing fluids with a high viscosity consisting of solid proppants. Therefore, a better understanding of how an induced fracture propagates under different conditions, such as different stress anisotropy coefficient, fracturing pressure, and azimuth, is fundamental for designing well spacing, well placement, and expected ultimate recovery [3-8].

The hydraulic fractures initiated from the drilling borehole are broadly used in petroleum engineering, in situ 
stress measurement, and geothermal development. Dong et al. [6] have proposed a theoretical model for hydraulic fracturing through a single radial perforation emanating from a borehole; however, two symmetrical radial cracks emanating from the borehole are more common in the hydraulic fracturing as shown in Figure 1(a). Mode-I stress intensity factor for symmetrical radial cracks emanating from hollow cylinder in an infinite plane is first solved with the weight function method by Jin et al. [9] who showed that the borehole radius affects the stress intensity factor and stress distribution at the radial crack tips, which consequently affects the crack initiation characteristics such as the fracture initiation angle and the critical water pressure. However, most studies neglected the borehole size and generally simplified the borehole and its associated symmetrical radial precracks as a straight-line fracture $[3,10]$. For instance, Chen et al. [2] characterized dynamic fracture propagation path during hydraulic fracturing by simplifying the model as a straight line, which was inconsistent with the actual experimental configuration. Behnia et al. [11] presented a boundary element method based on the higher order displacement discontinuity formulation to model the hydraulic fracture propagation in layered formations, in which the fracture was shaped being a straight line. The mechanical behavior of the line-shaped fracture under hydraulic pressure has been extensively conducted by various researchers such as Sobhaniaragh et al. [12], da Silva et al. [13], and Cheng et al. [14]. To study the effect of the hydraulic fracture initiated from a borehole, Zhang et al. [15] presented a $2 \mathrm{D}$ model for the initiation and growth of one or more hydraulic fractures from a well. They suggested that for complex multiple fracture cases, the misalignment angle and the number of initiated fractures are important in nearwellbore fracture path selection. Sesetty and Ghassemi [16] developed a 2D numerical model based on the displacement discontinuity method (DDM) and the fictitious stress method (FSM) to investigate the effect of rock anisotropy on wellbore stresses and hydraulic fracture propagation. Additionally, the pore pressure is also a critical factor affecting the hydraulic fracture behavior [17, 18]. Gholami et al. [19] investigated the effect of pore pressure on the hydraulic fracture propagation and indicated that a higher than average pore pressure zone accelerates the fracture growth, whereas a lower pressure anomaly zone resists a growing fracture. However, few fracture criteria have been proposed to study the fracture initiation by considering the internal rock pore pressure.

When a borehole with symmetric cracks is subjected to both external compressive load and inner water pressure, the stress intensity factors at the crack tips include those in both opening mode $\left(K_{\mathrm{I}}\right)$ and sliding mode $\left(K_{\mathrm{II}}\right)$. Many studies emphasized mathematical or numerical evolution of the opening mode stress intensity factor $\left(K_{\mathrm{I}}\right)$ for two symmetric cracks emanating from a circular hole when the maximum and minimum horizontal stresses (denoted by $\sigma_{\mathrm{H}}, \sigma_{\mathrm{h}}$ ) are tensile loads and the azimuth of the cracks is $0^{\circ}[20,21]$. However, when the azimuth of the cracks in Figure 1(a) is not zero, the uniaxial or biaxial tensile loading results in a plane shear stress condition, and both opening mode and the sliding mode stress intensity factor $\left(K_{\mathrm{I}}\right.$ and $\left.K_{\mathrm{II}}\right)$ are nonzero [22]. When the model shown in Figure 1(a) is subjected to compressive loading ( $\sigma_{\mathrm{H}}$ and $\sigma_{\mathrm{h}}$ are negative values) and both the pore pressure $(p)$ and the injected water pressure $(P)$ are considered, no theoretical work has been reported for calculating the stress intensity factors $\left(K_{\mathrm{I}}\right.$ and $\left.K_{\mathrm{II}}\right)$ under the combined loading conditions. Since it is critical to predict the accurate path of new fractures in the hydraulic fracturing operations and well production, the geometry and direction of the hydraulic fracture under the condition shown in Figure 1 (a) are theoretically studied by an analytical method in this work.

\section{Theoretical Model}

Dong et al. [6] have theoretically studied the feature of hydraulic fracturing through a single radial perforation emanating from a borehole. The results indicated that parameters such as the perforation length, the borehole radius, and the stress anisotropy coefficient significantly affect the critical water pressure and the critical initiation angle greatly. However, the fracture growth behavior of two symmetrical radial cracks (as shown in Figure 1(a)) is different from that of a single radial crack, which needs to be further investigated. Most of the existing studies assumed that the perforation was horizontal $\left(\beta=0^{\circ}\right)$. Consequently, the far-field equivalent shear stress has no influence on the mode-II stress intensity factors. The model shown in Figure 1(a) can be superposed by the models in Figures 1(b)-1(d). In addition, Figures 1(b) and 1(c) are the horizontal fractures subjected to far-field equivalent normal and shear stresses, respectively, whereas Figure 1(d) is the fracture subjected to injected water pressure and the pore pressure in rock. Since the perforation angle is zero, there is no mode-II stress intensity factor under the loading conditions shown in Figures 1(b) and 1(d), and only the loading conditions in Figure 1(c) lead to mode-II stress intensity factor.

For the model shown in Figure 1(b), the mode-I stress intensity factor caused by the far-field in situ stress is expressed by the following equation [20, 23]:

$$
\begin{aligned}
K_{\mathrm{I}-\sigma}=\sigma_{\mathrm{h}}^{\prime} \sqrt{\pi a} & \left\{\left(1-k^{\prime}\right)\left\{0.5\left(3-\frac{a}{R+a}\right)\left[1+1.243\left(1-\frac{a}{R+a}\right)^{2}\right]\right\}\right. \\
& \left.+k^{\prime}\left\{1+\left(1-\frac{a}{R+a}\right)\left[0.5+0.743\left(1-\frac{a}{R+a}\right)^{2}\right]\right\}\right\},
\end{aligned}
$$

where $\sigma_{\mathrm{h}}^{\prime}$ is the far-field equivalent maximum normal, $k^{\prime}$ is the equivalent stress anisotropy coefficient, and $a$ and $R$ are the perforation length and the borehole radius, respectively.

Following the convention in elastic mechanics, the tensile stress and dilatant strain are referred as positive, whereas the compressive stress and contractive strain are referred as negative in this study. Therefore, because the in situ stress shown in Figure 1(b) is compressive stress, the parameter $\sigma_{\mathrm{h}}^{\prime}$ in equation (1) is negative. According to the theory of elastic mechanics, for an inclined perforation 


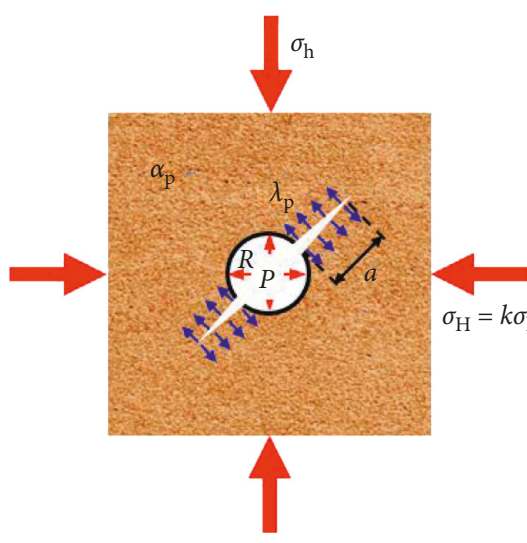

(a)

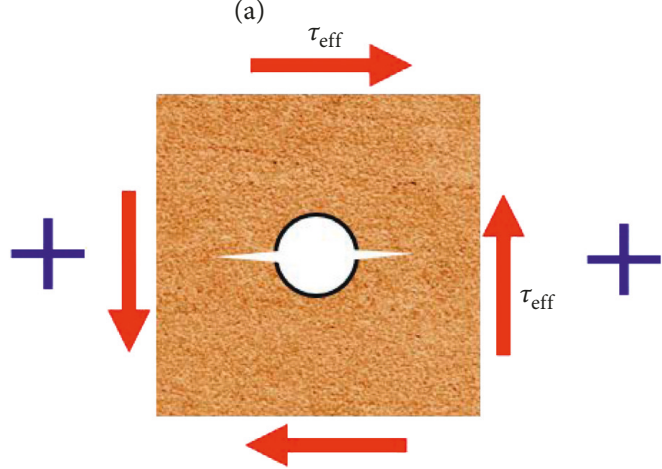

(c)

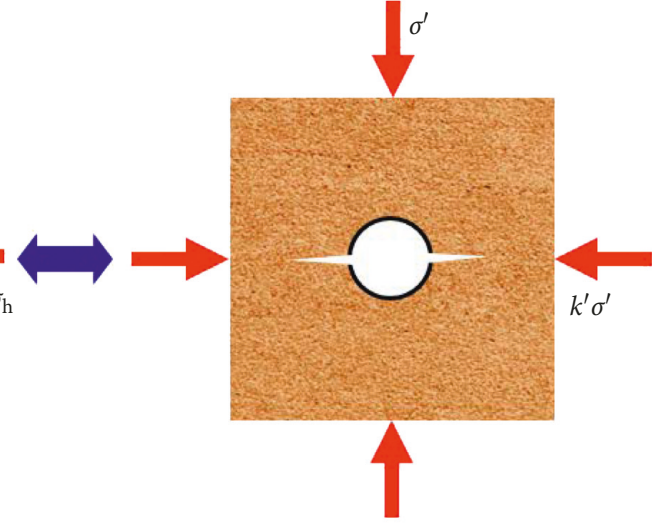

(b)

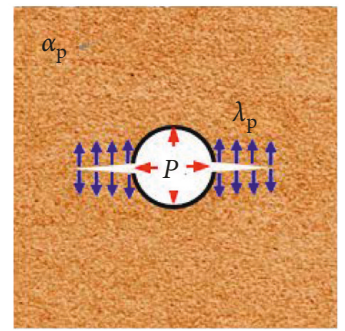

(d)

FIGURE 1: Loading conditions on two inclined symmetrical radial perforations emanating from a borehole. (a) can be created by superposing (b), (c), and (d).

angled $\beta$, the far-field equivalent maximum normal stress $\left(\sigma_{\mathrm{h}}^{\prime}\right)$ and far-field equivalent minimum normal stress $\left(\sigma_{\mathrm{H}}^{\prime}\right)$ are written as follows:

$$
\left\{\begin{array}{l}
\sigma_{\mathrm{H}}^{\prime}=\frac{\sigma_{\mathrm{h}} \sigma[(1+k)-(1-k) \cos 2 \beta]}{2}, \\
\sigma_{\mathrm{h}}^{\prime}=\frac{\sigma_{\mathrm{h}} \sigma[(1+k)+(1-k) \cos 2 \beta]}{2},
\end{array}\right.
$$

where $\sigma_{\mathrm{h}}$ is the minimum horizontal stress and $k$ is the ratio of the maximum horizontal stress to the minimum horizontal stress, $k=\sigma_{\mathrm{H}} / \sigma_{\mathrm{h}}$.

In addition, the equivalent stress anisotropy coefficient $\left(k^{\prime}\right)$ in Figure 1(b) can be expressed by equation (3), which represents the ratio of the far-field equivalent maximum normal stress to the far-field equivalent minimum normal stress, $k^{\prime}=\sigma_{\mathrm{H}}^{\prime} / \sigma_{\mathrm{h}}^{\prime}$.

$$
k^{\prime}=\frac{(1+k)-(1-k) \cos 2 \beta}{(1+k)+(1-k) \cos 2 \beta} .
$$

Several methods have been proposed to estimate stress intensity factors through the finite element method (FEM), in which the interaction integral method yields higher accuracy [24]. Hence, in this paper, the stress intensity factors are calculated by the interaction integral method, and for more details, refer to the ANSYS software manual [24].
For the model shown in Figure 1(c), it is subjected to a far-field equivalent shear stress which results in the mode-II stress intensity factor. For this loading condition, Hsu [22] theoretically studied the mode-II stress intensity factor for two radial cracks emanating from a circular hole in an infinite sheet under uniform in-plane shear loading, which is listed in Table 1. However, for small cracks with $a / R<0.1$, the mode-II stress intensity factor was unavailable from $\mathrm{Hsu}$ [22]. In this study, such values are numerically calculated by using the interaction integral method by ANSYS software which are marked by the star symbol $\left({ }^{*}\right)$ in Table 1 and plotted in Figure 2. Figure 2 shows the numerical results of stress intensity factor coefficient under different values of $a /(a+R)$, and the theoretical results are obtained from Hsu [22]. The results indicate that our numerical results agree well with the theoretical results.

According to Figure 2, the mode-II stress intensity factor at the tip of the fracture shown in Figure 1(c) can be fitted by the following equations:

$$
\begin{aligned}
& Y_{\text {II }}=3.127 x^{3}-7.5216 x^{2}+5.3936 x+0.0089, \\
& K_{\text {II }}=\tau_{\text {eff }} Y_{\text {II }} \sqrt{\pi a},
\end{aligned}
$$

where $Y_{\text {II }}$ is the normalized mode-II stress intensity factor, $x=a /(a+R)$, and $\tau_{\text {eff }}$ is the far-field equivalent shear stress. For an inclined perforation with the angle of $\beta$, the far-field equivalent shear stress can be written by as follows: 
TABLE 1: Normalized mode-II stress intensity factor for uniform in-plane shear [22].

\begin{tabular}{|c|c|c|c|c|c|c|c|c|c|c|}
\hline$\xi=a / \mathrm{R}$ & $0.01^{*}$ & $0.02^{*}$ & $0.03^{*}$ & $0.04^{*}$ & $0.05^{*}$ & $0.06^{*}$ & $0.07^{*}$ & $0.08^{*}$ & $0.09^{*}$ & 0.10 \\
\hline$F_{\mathrm{II}}$ & 0.0347 & 0.1137 & 0.1604 & 0.2242 & 0.2570 & 0.2970 & 0.3337 & 0.3726 & 0.4177 & 0.4310 \\
\hline$\xi=a / \mathrm{R}$ & 0.15 & 0.20 & 0.30 & 0.40 & 0.50 & 0.60 & 0.80 & 1.0 & 1.50 & 2.00 \\
\hline$F_{\mathrm{II}}$ & 0.5858 & 0.7114 & 0.8912 & 1.0086 & 1.0866 & 1.1380 & 1.1930 & 1.2134 & 1.2092 & 1.1854 \\
\hline$\xi=a / \mathrm{R}$ & 3.00 & 4.00 & 5.00 & 6.00 & 8.00 & 10.00 & 20.00 & $\infty$ & & \\
\hline$F_{\text {II }}$ & 1.1424 & 1.1130 & 1.0930 & 1.0788 & 1.0602 & 1.0486 & 1.0246 & 1.0000 & & \\
\hline
\end{tabular}

* Numerically calculated normalized mode-II stress intensity factors by ANSYS software using the interaction integral method.

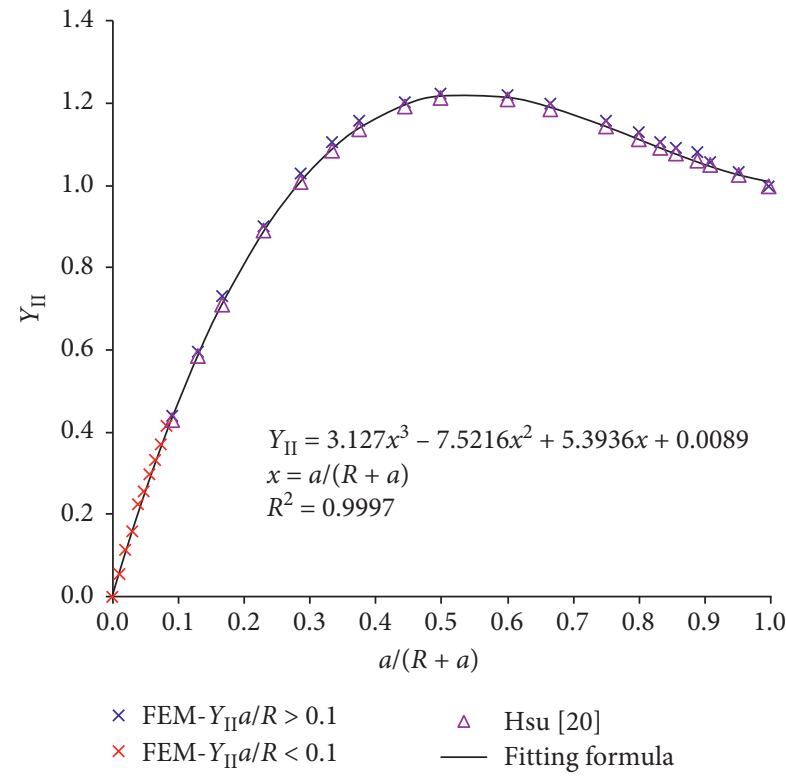

Figure 2: Normalized mode-II stress intensity factors.

$$
\tau_{\text {eff }}=\frac{\left[\sigma_{\mathrm{h}}(1-k) \sin 2 \beta\right]}{2} .
$$

Newman [20] and Tada et al. [23] theoretically derived the stress intensity factor formulae for the case shown in Figure $1(\mathrm{~d})$ without considering the pore pressure. The mode-I stress intensity factor in the model shown in Figure 1(d) can be given by the following equation $[20,23]$ :

$$
\begin{aligned}
K_{\mathrm{I}-\mathrm{P}}= & P \sqrt{\pi a}\left\{( 1 - \lambda ) ( 1 - \frac { a } { R + a } ) \left[0.637+0.485\left(1-\frac{a}{R+a}\right)^{2}\right.\right. \\
& \left.+0.4\left(\frac{a}{R+a}\right)^{2}\left(1-\frac{a}{R+a}\right)\right]+\lambda\left\{1+\left(1-\frac{a}{R+a}\right)\right. \\
& \left.\left.\cdot\left[0.5+0.743\left(1-\frac{a}{R+a}\right)^{2}\right]\right\}\right\},
\end{aligned}
$$

where $P$ is the water injection pressure and $\lambda$ is the ratio between the water pressures in the fracture and the borehole.

Based on equation (7), variation of the mode-I stress intensity factor with the perforation length $(a)$ can be written by equation (8), and the results are illustrated in Figure 3.

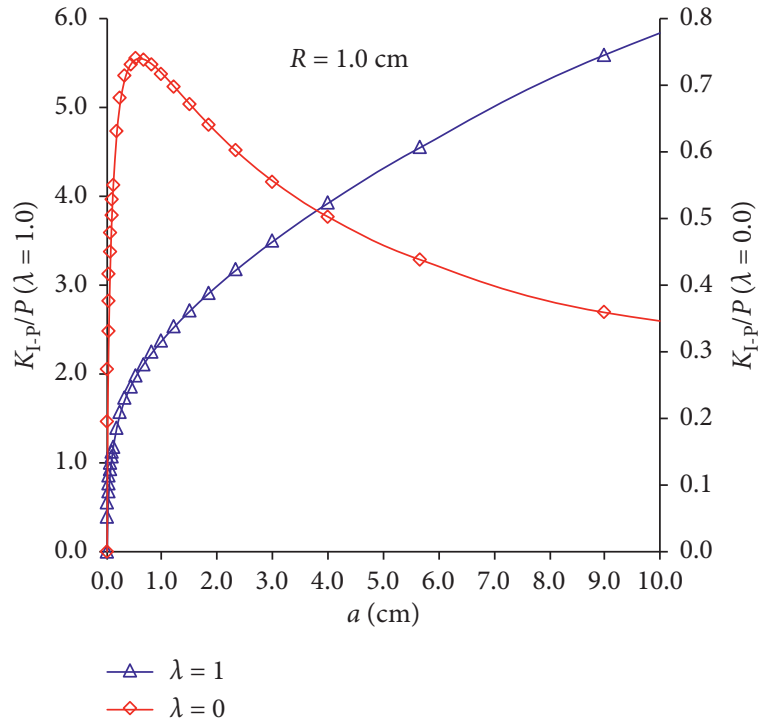

FIgURE 3: Variation of the mode-I stress intensity factor with the perforation length.

$$
\begin{aligned}
\left(Y_{\mathrm{I}-\mathrm{P}}\right)_{\mathrm{a}}= & \frac{K_{\mathrm{I}-\mathrm{P}}}{P}=\sqrt{\pi a}\left\{(1-\lambda)\left(1-\frac{a}{R+a}\right)\right. \\
& \cdot\left[0.637+0.485\left(1-\frac{a}{R+a}\right)^{2}+0.4\left(\frac{a}{R+a}\right)^{2}\left(1-\frac{a}{R+a}\right)\right] \\
& \left.+\lambda\left\{1+\left(1-\frac{a}{R+a}\right)\left[0.5+0.743\left(1-\frac{a}{R+a}\right)^{2}\right]\right\}\right\} .
\end{aligned}
$$

According to Figure 3, in the case of $\lambda=1$ (the hydraulic pressure acts all over the fracture surface), the stress intensity factor monotonically increases along the crack from the borehole to the perforation tip and the borehole radius is assumed constant $(R=1 \mathrm{~cm})$. Thus, the fracture propagates continuously once it is initiated. On the other hand, in the case of $\lambda=0$ (the hydraulic pressure acts only inside the borehole), there is a critical point, before which the stress intensity factor increases with the increment of the crack length from the borehole to the perforation tip. After the critical point, the stress intensity factor decreases along the crack length from the borehole to the perforation tip. Therefore, when high-viscosity fluid is used as the fracturing fluid, the stress intensity factors may not reach the fracture toughness, even if the perforation length increases. Hence, the fracture will not propagate unless the water injection pressure is increased to enlarge the value of stress intensity factor. This conclusion has also been demonstrated by the numerical 
results in Zhang et al. [25], who showed that a high value of fluid viscosity would lead to high breakdown pressure.

According to equation (7), the critical point when $\lambda=0$ can be evaluated by the following equation:

$$
\left.\frac{\partial K_{\mathrm{I}-\mathrm{P}}}{\partial(a / R+a)}\right|_{\lambda=0}=0 \text {. }
$$

The solution of equation (9) shows that $a / R=0.589$ is the critical point. It means that, in the case of $\lambda=0$, when $a / R<0.589$, the stress intensity factor increases with the increment of the crack length from the borehole to the crack tip, but it decreases when $a / R>0.589$. Therefore, for an initially short perforation with $a / R<0.589$, if the input water pressure is larger than the fracture initiation stress, the fracture will extend without an additional pressure till the crack length exceeds $0.589 R$.

Figure 4 shows the relationship between the normalized mode-I stress intensity factor $\left(K_{\mathrm{I}-\mathrm{P}} / P(\pi a)^{0.5}\right)$ and the normalized perforation length $(a /(R+a))$ for different values of the parameter $\lambda$. The results indicate that the value of $K_{\mathrm{I}-\mathrm{P}} / P(\pi a)^{0.5}$ increases as $\lambda$ increases for the same $a /(R+a) . a /(R+a) \longrightarrow 0$ or $a \ll R, K_{\mathrm{I}-\mathrm{P}} / P(\pi a)^{0.5}=1.122$ and 2.243 for $\lambda=0$ and 1 , respectively, which indicates the existence of the borehole enlarges the stress intensity factors many times no matter the water flows into the fracture or not. However, $a /(R+a) \longrightarrow 1$ or $a \gg R, K_{\mathrm{I}-\mathrm{P}} /$ $P(\pi a)^{0.5}=0$ and 1 for $\lambda=0$ and 1 , respectively, which indicates the borehole can be ignored if the perforation length is much greater than the borehole radius. For such case, the stress intensity factor equals $P \sqrt{\pi a}$.

For the case with a borehole, there is no theoretical equation available to estimate the mode-I stress intensity factor caused by the pore pressure $(\alpha \mathrm{p})$ shown in Figure 1(d). The widely used weight function which only depends on the model geometry and crack type is developed to determine the stress intensity factor. If the weight function for the model is known, the associated stress intensity factors can be obtained by multiplying this function by the stress distribution in the intact body and integrating it along the crack length $[9,26]$. Hence, in this paper, the mode-I stress intensity factor caused by pore pressure was calculated through the weight function method. The weight function is only dependent on fracture geometry to an integration expression as follows:

$$
\begin{aligned}
K_{\mathrm{I}}= & \int_{0}^{a} \sigma(x) m(x, a) d x, \\
m(a, x)= & \frac{2}{\sqrt{2 \pi(a-x)}}\left[1+M_{1}\left(1-\frac{x}{a}\right)^{1 / 2}+M_{2}\left(1-\frac{x}{a}\right)\right. \\
& \left.+M_{3}\left(1-\frac{x}{a}\right)^{3 / 2}\right],
\end{aligned}
$$

where $\sigma(x)$ is the stress field resulting from the loads applied on the uncracked body, normal to the faces of the

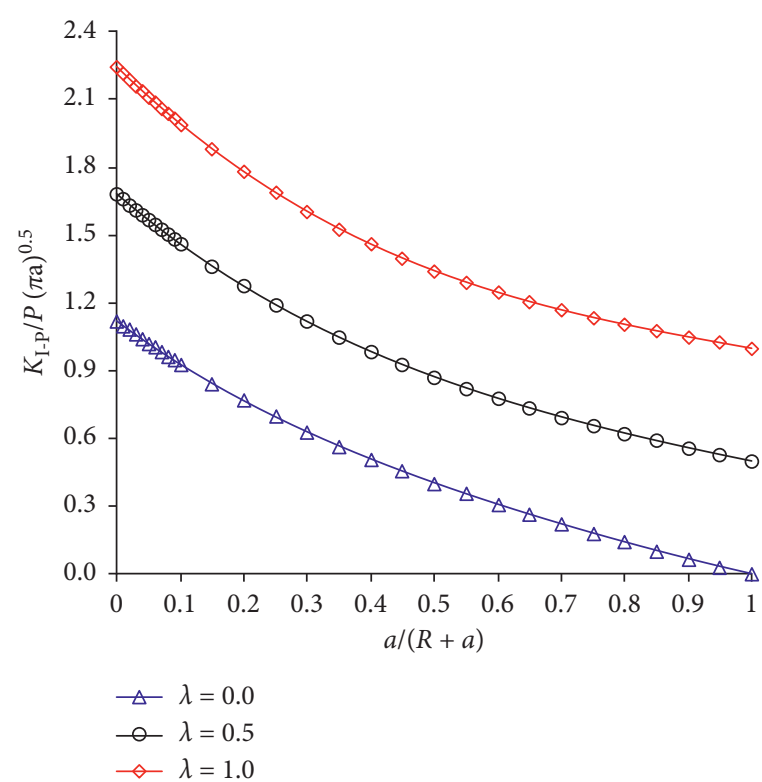

FIgURE 4: Normalized mode-I stress intensity factor.

prospective crack, $m(x, a)$ is a weight function, in which $x$ is a dummy variable, and $M_{1}, M_{2}$, and $M_{3}$ are weight function parameters.

To obtain the universal weight function $m(x, a)$ in equation (11) for a particular cracked body, it is necessary to determine the three parameters $M_{1}, M_{2}$, and $M_{3}$. For an infinite plate with two symmetric cracks emanating from a borehole, Jin et al. [9] determined these three parameters which can be written by

$$
\begin{aligned}
M_{1}= & 0.074 x_{1}^{5}-0.1765 x_{1}^{4}-0.3516 x_{1}^{3}+0.82 x_{1}^{2} \\
& +0.2964 x_{1}-0.4255, \\
M_{2}= & -0.196 x_{1}^{5}+0.3508 x_{1}^{4}+0.9246 x_{1}^{3}-1.5545 x_{1}^{2} \\
& -0.9476 x_{1}+0.7175, \\
M_{3}= & 0.098 x_{1}^{5}-0.1754 x_{1}^{4}-0.4623 x_{1}^{3}+0.7772 x_{1}^{2} \\
& +0.4738 x_{1}+0.1413,
\end{aligned}
$$

where $x_{1}=\log _{10}(a / R)$ and $0.001 \leq a / R \leq 100$.

For the loading condition with pore pressure, $\sigma(x)$ in equation (10) becomes $\alpha \mathrm{p}$. According to equations (10)-(14), the stress intensity factor caused by the pore pressure can be given by the following equation:

$$
K_{\mathrm{I}-\alpha \mathrm{p}}^{(1)}=\alpha p \sqrt{\pi a} \cdot \frac{\sqrt{2}}{\pi}\left(2+M_{1}+\frac{2}{3} M_{2}+\frac{1}{2} M_{3}\right) .
$$

Figure 5 depicts the relationship between the normalized mode-I stress intensity factor caused by the pore pressure and the normalized crack length $(a /(a+R))$. Then, it can be well predicted by the following equations: 


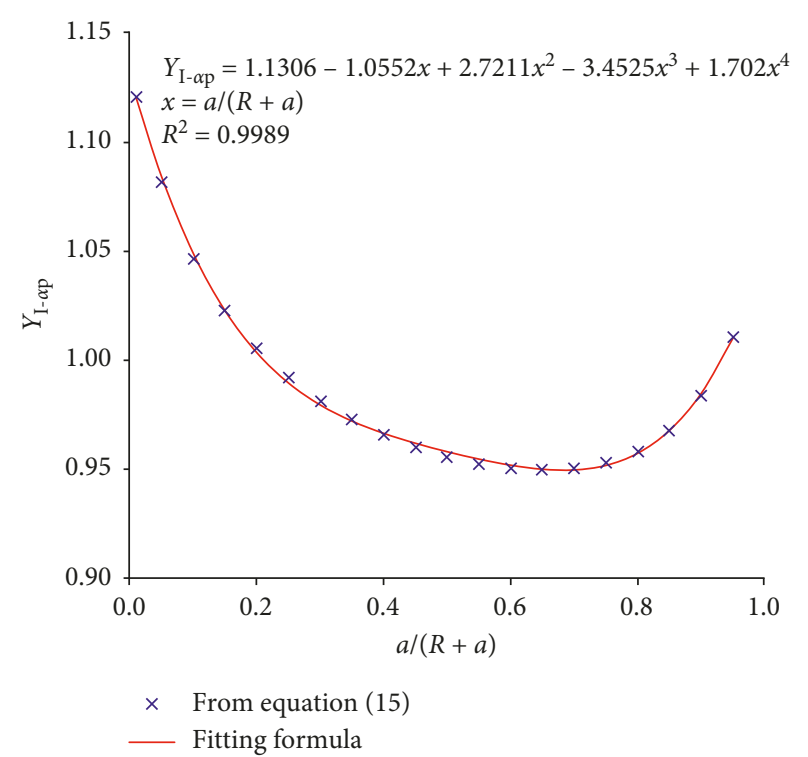

FIGURE 5: Normalized mode-I stress intensity factor caused by pore pressure.

$$
\begin{aligned}
Y_{\mathrm{I}-\alpha \mathrm{p}}= & \frac{K_{\mathrm{I}-\alpha \mathrm{p}}}{\alpha p \sqrt{\pi a}}=1.1306-1.0552\left(\frac{a}{R+a}\right)+2.7211\left(\frac{a}{R+a}\right)^{2} \\
& -3.4525\left(\frac{a}{R+a}\right)^{3}+1.702\left(\frac{a}{R+a}\right)^{4},
\end{aligned}
$$

$K_{\mathrm{I}-\alpha \mathrm{p}}=\alpha p \sqrt{\pi a} K_{\mathrm{I}-\alpha \mathrm{p}}$.

It can be seen from equations (16) and (17) that the value of $K_{\mathrm{I}-\alpha \mathrm{p}}$ increases as the pore pressure increases, which has a positive effect on the hydraulic fracture initiation and reduces the required pressure. According to the abovementioned discussion on the stress intensity factors under various cases, the mode-I stress intensity factor caused by the loading conditions in Figure 1 can be evaluated by the sum of equations (1), (7), and (17) as follows:

$$
K_{\mathrm{I}}=K_{\mathrm{I}-\sigma}+K_{\mathrm{I}-P}+K_{\mathrm{I}-\alpha \mathrm{p}}
$$

According to fracture mechanics, the stress field surrounding the fracture tip in the polar coordinate system shown in Figure 6 can be given by the following equation:

$$
\left\{\begin{array}{l}
\sigma_{\mathrm{r}}=\frac{1}{2 \sqrt{2 \pi r}}\left[K_{\mathrm{I}} \cos \frac{\theta}{2}(3-\cos \theta)+K_{\mathrm{II}} \sin \frac{\theta}{2}(3 \cos \theta-1)\right], \\
\sigma_{\theta}=\frac{1}{2 \sqrt{2 \pi r}} \cos \frac{\theta}{2}\left[K_{\mathrm{I}}(1+\cos \theta)-3 K_{\mathrm{II}} \sin \theta\right] \\
\tau_{\mathrm{r} \theta}=\frac{1}{2 \sqrt{2 \pi r}} \cos \frac{\theta}{2}\left[K_{\mathrm{I}} \sin \theta+K_{\mathrm{II}}(3 \cos \theta-1)\right],
\end{array}\right.
$$

where $\mathrm{r}$ and $\theta$ are the polar coordinates originating at the fracture tip and the line of extension, respectively. The stress intensity factors $K_{\mathrm{I}}$ and $K_{\mathrm{II}}$ in equation (19) for the model

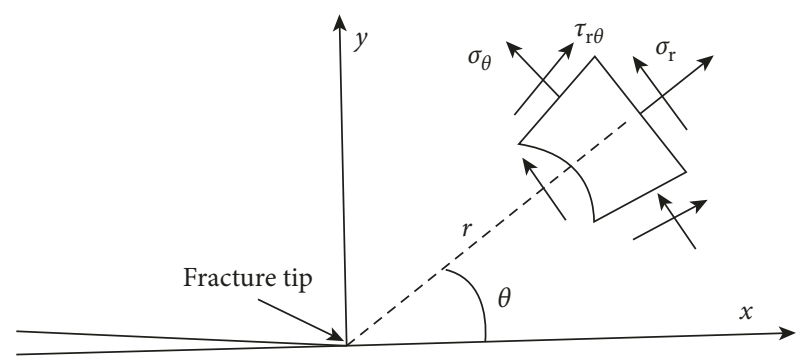

Figure 6: Stresses at the fracture tip.

shown in Figure 1 can obtained by equations (18) and (5), respectively.

To study the effects of combined loadings on the fracture initiation, several mixed-mode fracture criteria have been proposed and verified under specific experimental conditions. For tensile cracking, the maximum tangential stress criterion (MTS-criterion) proposed by Erdogan and Sih [27] is the simplest one and is widely used. The MTS criterion states that the fracture initiation direction coincides with the direction of the maximum tangential stress along a constant radius around the crack tip. Generally, the MTS criterion provides accurate results for tensile fracture in most brittle materials, including rock [28]. The fracture initiation direction $\theta_{c}$ according to the MTS criterion can be found from the conditions specified by the following equation:

$$
\begin{gathered}
\sigma_{\theta}>0 \\
\frac{\partial \sigma_{\theta}}{\partial \theta}=0 \\
\frac{\partial^{2} \sigma_{\theta}}{\partial \theta^{2}}<0 .
\end{gathered}
$$

By substituting the stress field in equation (19) into the MTS criterion in equation (20), equation (21) is obtained:

$$
\left\{\begin{array}{l}
\cos \frac{\theta_{\mathrm{c}}}{2}\left[K_{\mathrm{I}}\left(1+\cos \theta_{\mathrm{c}}\right)-3 K_{\mathrm{II}} \sin \theta_{\mathrm{c}}\right]>0, \\
3 \cos \frac{\theta}{2}\left[K_{\mathrm{I}} \sin \theta+K_{\mathrm{II}}(3 \cos \theta-1)\right]=0 \\
3 \sin \frac{\theta}{2}\left[K_{\mathrm{I}} \sin \theta+K_{\mathrm{II}}(3 \cos \theta-1)\right] \\
-6 \cos \frac{\theta}{2}\left[K_{\mathrm{I}} \cos \theta-3 K_{\mathrm{II}} \sin \theta\right]<0 .
\end{array}\right.
$$

Solving equation (21) to obtain the fracture initiation angle $\theta_{c}$, equation (22) is obtained:

$$
\theta_{\mathrm{c}}= \begin{cases}0, & K_{\mathrm{II}}=0, \\ 2 \arctan \left[\frac{\left(K_{\mathrm{I}}-\sqrt{K_{\mathrm{I}}^{2}+8 K_{\mathrm{II}}^{2}}\right)}{4 K_{\mathrm{II}}}\right], & K_{\mathrm{II}} \neq 0,\end{cases}
$$


where the fracture initiation angle $\left(\theta_{c}\right)$ is referred as positive when it is measured along the counterclockwise direction and negative when clockwise. Equation (22) indicates that under the case of the pure mode-I fracture, i.e., $K_{\mathrm{II}}=0$, the fracture initiates along its original direction, i.e., $\theta_{c}=0$. However, under the case of mix-mode fracture, i.e., $K_{\mathrm{II}} \neq 0$, the fracture initiation angle depends on the positive or negative $K_{\mathrm{II}}$. The negative $K_{\mathrm{II}}$ causes the positive value of fracture initiation angle while the positive $K_{\mathrm{II}}$ results in the negative value of fracture initiation angle.

Moreover, equation (23) can be obtained according to the second formula in equation (18):

$$
\left(\sigma_{\theta}\right)_{\max } \sqrt{2 \pi r}=\frac{1}{2} \cos \frac{\theta_{c}}{2}\left[K_{\mathrm{I}}\left(1+\cos \theta_{\mathrm{c}}\right)-3 K_{\mathrm{II}} \sin \theta_{\mathrm{c}}\right] .
$$

By substituting equation (22) into equation (23),

$$
\left(\sigma_{\theta}\right)_{\max } \sqrt{2 \pi r}= \begin{cases}K_{\mathrm{I}}, & K_{\mathrm{II}}=0, \\ 4 \sqrt{2}\left|K_{\mathrm{II}}\right|^{3}\left(K_{\mathrm{I}}+3 \sqrt{8 K_{\mathrm{II}}^{2}+K_{\mathrm{I}}^{2}}\right)\left(K_{\mathrm{I}}^{2}-K_{\mathrm{I}} \sqrt{8 K_{\mathrm{II}}^{2}+K_{\mathrm{I}}^{2}}+12 K_{\mathrm{II}}^{2}\right)^{-3 / 2}, & K_{\mathrm{II}} \neq 0 .\end{cases}
$$

According to fracture mechanics, the mode-I fracture toughness $K_{\mathrm{IC}}$ can be obtained from equation (25), which is an important parameter of the mechanical properties of rocks and describes the material's resistance to crack propagation.

$$
K_{\mathrm{IC}}=\sigma_{\mathrm{t}} \sqrt{2 \pi r}=\left(\sigma_{\theta}\right)_{\max } \sqrt{2 \pi r},
$$

where $\sigma_{\mathrm{t}}$ is the critical tensile strength.

When the water injection pressure reaches the critical water pressure $P_{\mathcal{c}}$, the tangential stress $\sigma_{\theta}$ reaches its maximum value, which equals the tensile strength $\left(\sigma_{t}\right)$ of the rock. Hence, according to equations (24) and (25), the critical water pressure can be obtained from equation (26).

$$
K_{\mathrm{IC}}=K_{\mathrm{eq}}= \begin{cases}K_{\mathrm{I}}, & K_{\mathrm{II}}=0, \\ 4 \sqrt{2}\left|K_{\mathrm{II}}\right|^{3}\left(K_{\mathrm{I}}+3 \sqrt{8 K_{\mathrm{II}}^{2}+K_{\mathrm{I}}^{2}}\right)\left(K_{\mathrm{I}}^{2}-K_{\mathrm{I}} \sqrt{8 K_{\mathrm{II}}^{2}+K_{\mathrm{I}}^{2}}+12 K_{\mathrm{II}}^{2}\right)^{-3 / 2}, & K_{\mathrm{II}} \neq 0,\end{cases}
$$

where $K_{\text {eq }}$ is the equivalent stress intensity factor.

The fracture criterion used in this study assumes that the propagation direction is along a direction normal to the maximum tangential tensile stress, and when the equivalent stress intensity factor $K_{\text {eq }}$ is greater than or equal to the fracture toughness of the rock, $K_{\mathrm{IC}}$, the fracture propagates. Thus, equation (26) is an explicit solution for the critical water pressure $P_{c}$, which can be easily applied in practice. Conventional approaches commonly assume that the hydraulic fracture initiates and propagates under the condition that is controlled by the mode-I (opening) stress intensity factor, i.e., $K_{\mathrm{I}}$, reaches the value of the critical stress intensity factor or the fracture toughness, i.e., $K_{\text {IC }}$. Such a model predicts that no fracturing will occur until $K_{\mathrm{I}}=K_{\mathrm{IC}}$. For example, Mogilevskaya et al. [29] studied the hydraulic fracturing, in which the critical water pressure was determined by adjusting the uniform pressure on the boundary of a wellbore to meet the condition of $K_{\mathrm{I}}=K_{\mathrm{IC}}$ and the extension angle was determined by assuming $K_{\mathrm{II}}=0$. Such method was also implemented in many numerical works conducted by researchers such as Lecampion and Desroches [30], Zhang et al. [15], Bao et al. [31], and Garagash [32]. Thus, these studies have unanimously ignored the effect of $K_{\mathrm{II}}$ caused by the far-field in situ stress on the critical water pressure, which is only applicable given the condition that the perforation is perpendicular or parallel to the principal stress, i.e., there is no effect of the equivalent shear stress in the model. However, in the hydraulic fracturing engineering practice, the actual perforation angle is not always parallel to the orientation of the maximum horizontal stress and the appearance of the shear stress is inevitable, i.e., $K_{\mathrm{II}} \neq 0$. In addition, equation (26) indicates that $K_{\mathrm{II}}$ is an important factor affecting the hydraulic fracture initiation. The equivalent stress intensity factor $K_{\mathrm{eq}}$ conveniently addresses the effect of both $K_{\mathrm{I}}$ and $K_{\mathrm{II}}$ on the critical injected water pressure.

\section{Validations}

To validate the proposed theoretical model, the experimental data from Chen et al. [2] and Jin [33] are used for validation. In the experiments, the samples were made of cement and quartz sand at the volume ratio of $1: 1$ with a block size of $300 \mathrm{~mm} \times 300 \mathrm{~mm} \times 300 \mathrm{~mm}$. The preexisting perforation length was $a=30 \mathrm{~mm}$, and the borehole diameter was $R=15 \mathrm{~mm}$. For numerical replication, only a 2D model with a size of $300 \mathrm{~mm} \times 300 \mathrm{~mm}$ as illustrated in Figure 1(a) was used to investigate the hydraulic fracture initiation. The minimum horizontal stress (i.e., $\sigma_{\mathrm{h}}$ shown in Figure 1(a)) was 1.0 MPa. Two types of maximum horizontal stresses (i.e., $\sigma_{\mathrm{H}}$ shown in Figure 1(a)) were used in the experiments, i.e., $4 \mathrm{MPa}$ and $6 \mathrm{MPa}$, respectively. There was no pore pressure in the block specimens, i.e., $K_{\mathrm{I}-\alpha \mathrm{p}}=0$. Based on the experiments, Jin [33] suggested that the fracture initiation angle was zero when the perforation orientation was perpendicular to the plane of the minimum 
horizontal stress, and the newly created fracture propagates to the direction perpendicular to the minimum horizontal principal stress.

According to the parameters in the experiments, the critical water pressure and critical initiation angle are calculated theoretically by equations (26) and (22), respectively, which are also shown in Figure 7 together with the experimental results. In Figure 7, the parameter $k$ is the stress anisotropy coefficient defined in Figure 1(a). It can be seen from Figure 7 (a) that when $k=4$, the theoretical results of the critical water pressure agree well with those obtained from the experiments (the blue and red lines). As shown in Figure 7(b), the theoretical results of the critical water pressure are consistent with the experimental results when the perforation angles equal $30^{\circ}$ and $60^{\circ}$, respectively. However, when $\beta=15^{\circ}$, the difference between the theoretical and the experimental result is roughly $1.8 \mathrm{MPa}$. For the critical initiation angle shown in Figure $7(\mathrm{c})$, the theoretical and experimental data also fit well with each other except for the azimuth of the fracture $\beta=45^{\circ}$, in which the difference is about $4.5^{\circ}$. When $k=6$, the theoretical results of the critical water pressure agree with the experimental data at $\beta=30^{\circ}$ and $45^{\circ}$, while at two other perforation angles (i.e., $\beta=15^{\circ}$ and $60^{\circ}$ ), the differences are significant for both the critical water pressure and critical initiation angle. The discrepancies between the theoretical and experimental results are possibly caused by following reasons: (1) the theoretical model is simplified from the practical experiments, which may result in the experimental conditions that cannot be fully realized by the theoretical model. (2) Due to the heterogeneity of the mortar blocks in the experiment (such as micropores, pores, cracks, etc.), the critical water pressures obtained in the hydraulic fracturing experiments may have a certain range, whereas the theoretical calculation assumes the material be homogeneous. (3) Some inherent errors in the experimental measurements are unavoidable. It is worth mentioning that an advantage of the presented theoretical model lies in its capability to investigate fracture initiation in homogeneous rocks. By considering the rock material heterogeneity, incorporating the proposed model into the numerical model benefits understanding the initiation and growth of hydraulic fracture in heterogeneous material, which potentially broadens the application of the present study.

To further compare the theoretical and experimental results, the experimental results of the critical water pressure are substituted into equation (22) to calculate the theoretical results of the fracture initiation angle for both $k=4$ and $k=6$, which are plotted in Figure 7 (c) and labelled "Theoretical with EXP-P." For both $k=4$ and $k=6$, the theoretical predictions in the data series of "Theoretical with EXP-P" are much closer to the experimental results. For example, when $k=6$ and $\beta=15^{\circ}$, the differences between the theoretical and experimental results are reduced from $36 \%$ to $12 \%$ if the experimental results of the critical water pressure are substituted into equation (22) to calculate the critical initiation angle. Similarly, when $k=6$ and $\beta=60^{\circ}$, the theoretical fracture initiation angle is in good agreement with the experimental results.
The comparisons between the theoretical results obtained for $k=4$ and $k=6$ indicate that the horizontal stress anisotropy coefficient $(k)$ has a great influence on the fracture initiation. The larger the horizontal stress anisotropy coefficient, the shorter the distance of the reoriented fracture away from the maximum horizontal stress. The overall good agreement between the theoretical and experimental results shown in Figure 7 indicates that the theoretical model proposed in this study can quantitatively predict the critical water pressure and fracture initiation angle for the hydraulic fracturing model with the symmetrical perforation emanating from a borehole. The effect of different parameters on the critical water pressure and fracture initiation angle is discussed in the following.

\section{Theoretical Results of the Hydraulic Fracture Initiation}

Section 2 shows that the proposed theoretical model requires several input parameters. They are the far-field minimum and maximum horizontal stresses $\sigma_{\mathrm{h}}$ and $\sigma_{\mathrm{H}}$, where $\sigma_{\mathrm{H}}=k \sigma_{\mathrm{h}}$, the perforation angle and length, the borehole radius, Biot's coefficient, the pore pressure, the ratio of the water pressure in the fracture and borehole, and the mode-I fracture toughness. All the parameters are directly measurable experimentally. In the following sections, the effects of these parameters on the critical water pressure and critical initiation angle in hydraulic fracturing engineering practice are discussed, in which the mode-I fracture toughness $K_{\mathrm{IC}}$ of the rock is assumed to be $2.1 \mathrm{MPa} \cdot \mathrm{m}^{1 / 2}$ [34].

4.1. Effect of Stress Anisotropy Coefficient. The ratio between two horizontal stresses shown in Figure 1(a) affects significantly the fracture dynamic reorientation. The larger the stress anisotropy coefficient, the shorter the distance of the reoriented fracture away from the maximum horizontal stress [2]. However, there were no systematical analytical studies on the effect of the stress anisotropy coefficient on the critical water pressure and critical initiation angle for the model of a pressurized two symmetric radial perforations emanating from a borehole. In this study, the stress anisotropy coefficient is defined as the ratio of the maximum to minimum horizontal stresses and denoted by the parameter $k$ which is illustrated in Figure 1(a). The minimum horizontal stress is kept constant, and hence the different values $k$ of the stress anisotropy coefficient are obtained by changing the maximum horizontal stress. The obtained results are depicted in Figure 8, in which 8(a)-8(c) illustrate the effect of stress anisotropy coefficient on the critical water pressure under different perforation lengths, i.e., $a=10 \mathrm{~mm}, 100 \mathrm{~mm}$, respectively, while 8 (b) -8 (d) show the corresponding critical initiation angle. All other input parameters are presented in these figures.

It can be seen from Figure 8 (a) that when $k=1$, i.e., in the hydrostatic stress state, the value of critical water pressure remains constant for all the perforation angle ranging from $0^{\circ} \sim 90^{\circ}$. For all other stress ratios $k \neq 1$, when $\beta=0^{\circ}$, the water pressure reaches the critical water pressure which will result 


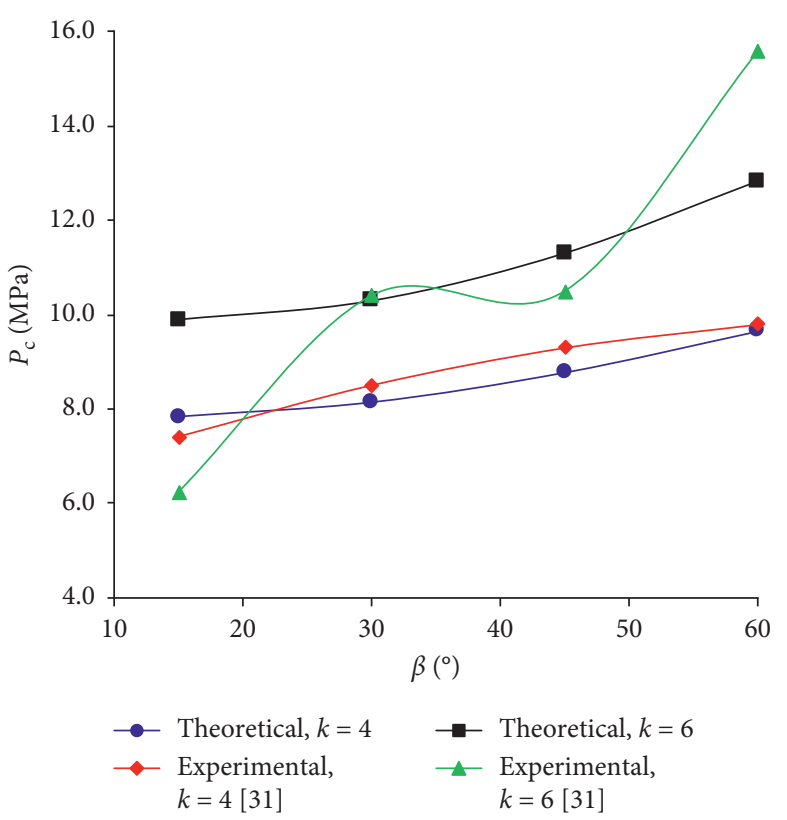

(a)

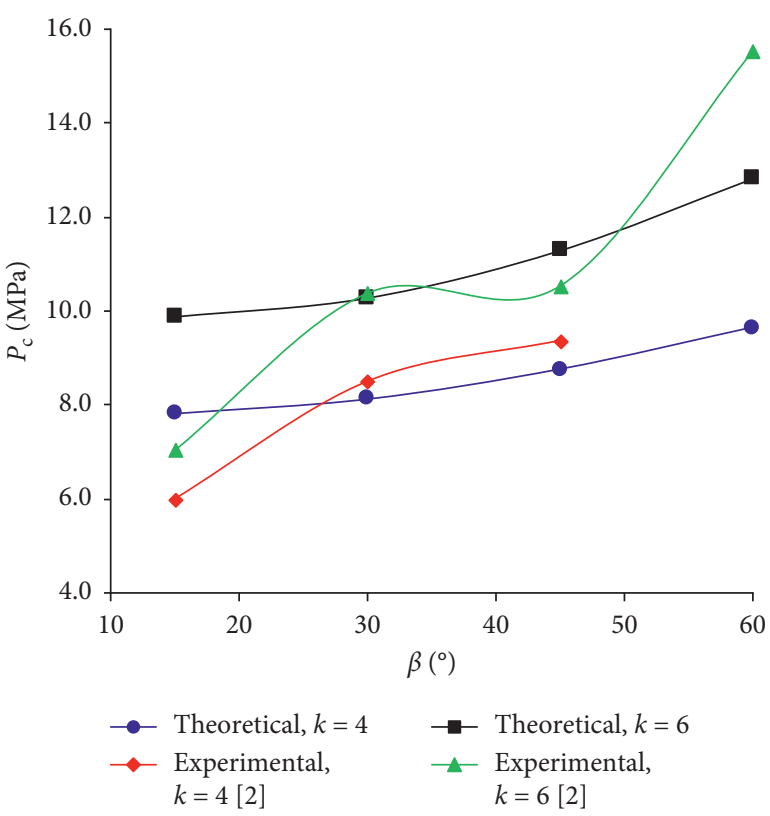

(b)

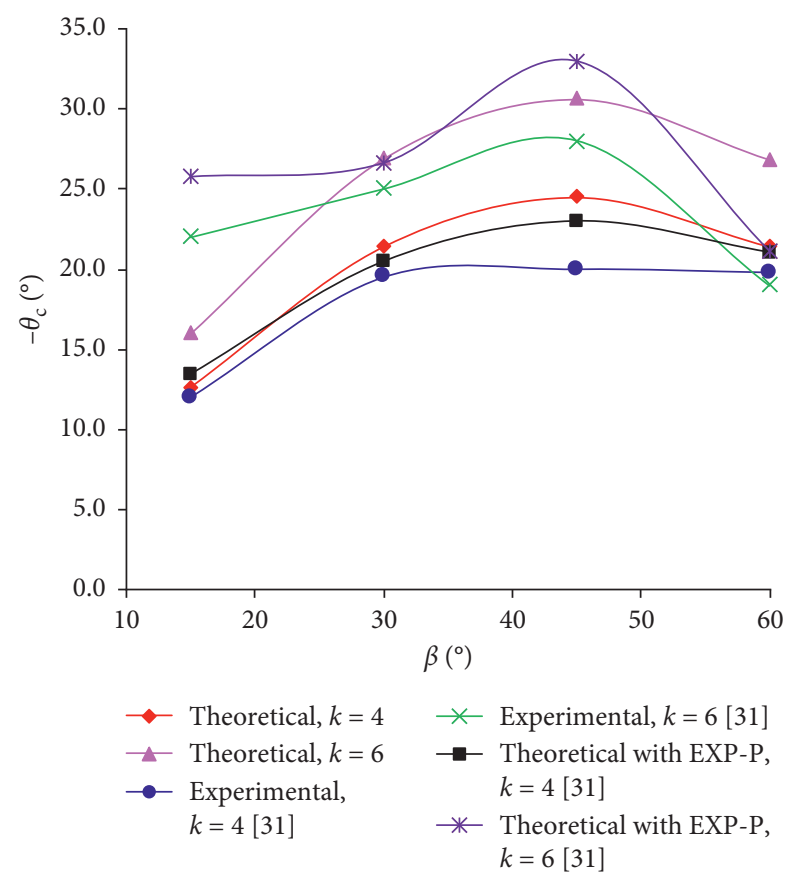

(c)

Figure 7: Comparison of the critical water pressure and critical initiation angle obtained by using the theoretical model and the experimental tests obtained from Chen et al. [2] and Jin [33].

in the fracture propagation in the direction parallel to the maximum horizontal stress. As the perforation angle increases, the critical water pressure increases gradually. This theoretical conclusion has also been demonstrated by the numerical results obtained by Sepehri et al. [4], who showed that the breakdown pressure increases as the perforation azimuth increases. When the perforating direction is perpendicular to the maximum horizontal stress $\left(\beta=90^{\circ}\right)$, the critical water pressure reaches the maximum value.
Figure 8(a) shows that there is an intersection point $\left(\beta_{0}\right)$ between the curves with different stress anisotropy coefficients, where the critical water pressure decreases with the increment of stress anisotropy coefficient when $0^{\circ} \leq \beta \leq \beta_{0}$, while it shows the opposite trend when $\beta_{0} \leq \beta \leq 90^{\circ}$. What is the reason that there is an intersection point $\beta_{0}$ for different stress anisotropy coefficients when $a=10 \mathrm{~mm}$ ? Equations (18) and (5) indicate that $K_{\mathrm{I}-\sigma}$ and $K_{\mathrm{II}}$ depend on the perforation angle. Both the equivalent normal 


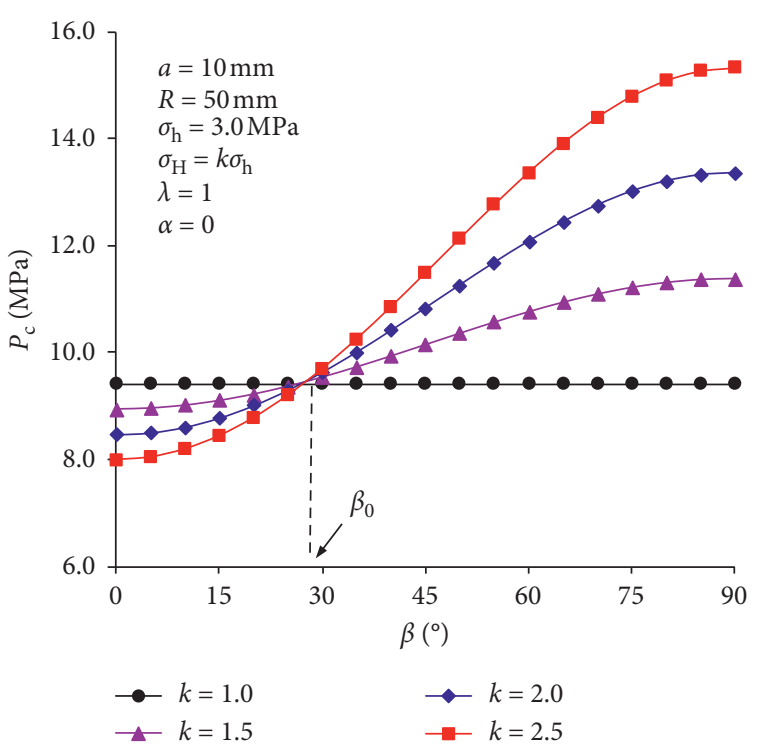

(a)

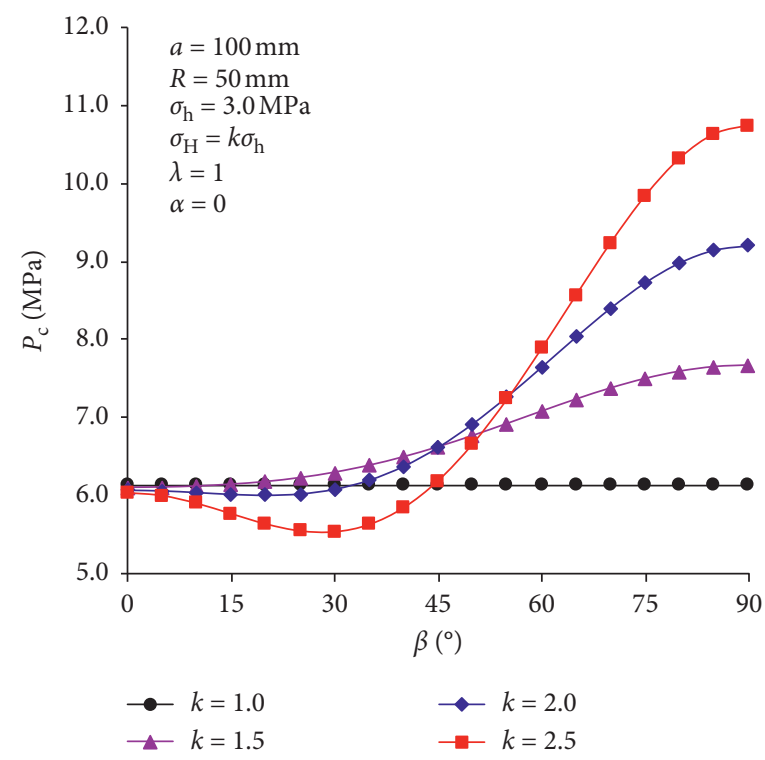

(c)

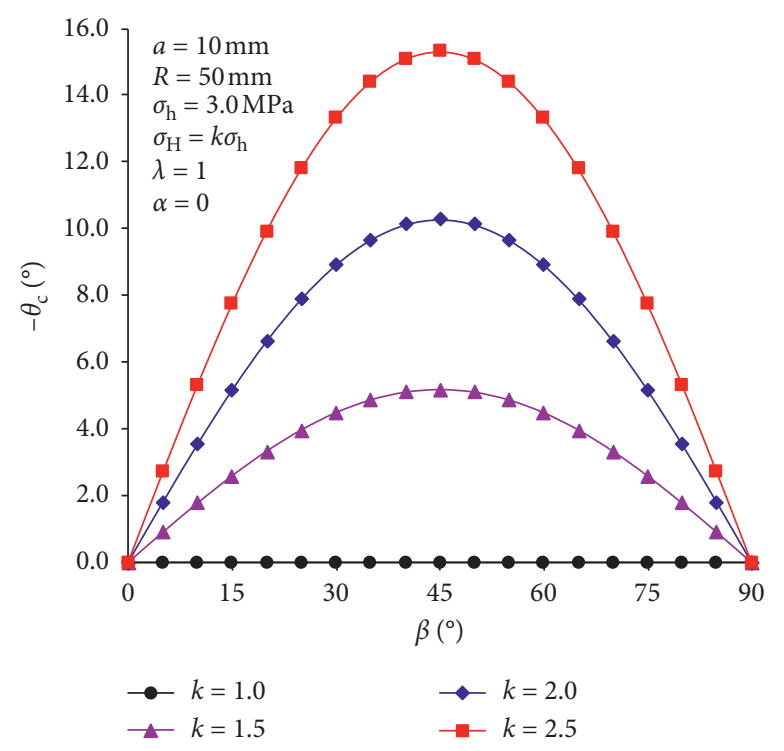

(b)

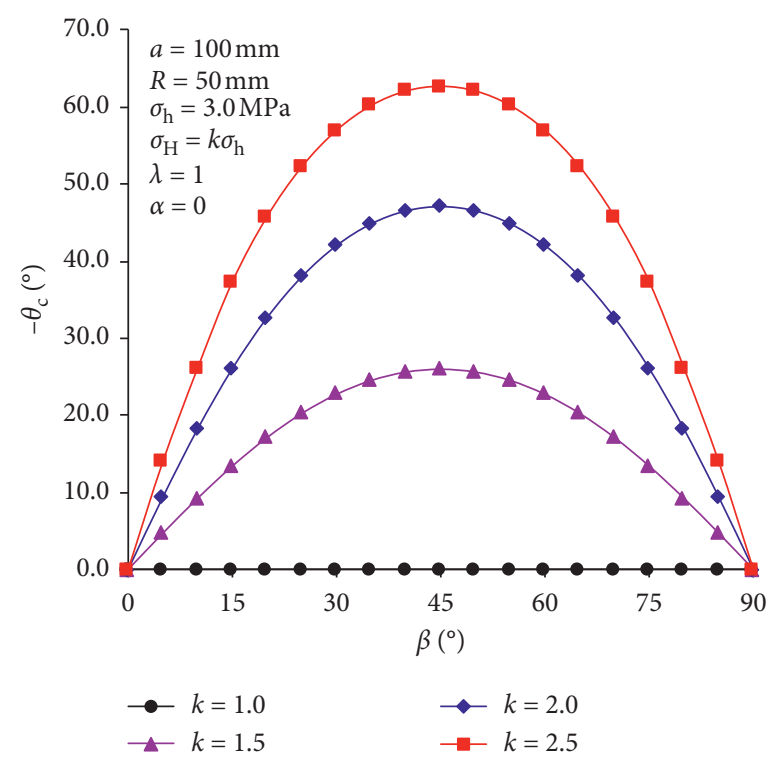

(d)

FIgURE 8: Effect of the stress anisotropy coefficient on the critical water pressure and critical initiation angle.

stresses $\left(\sigma^{\prime}\right)$ and $K_{\mathrm{II}}$ shown in equations (2) and (5) are symmetrical at $\beta=45^{\circ}$ which is not the reason for the existence of the transitional azimuth $\beta_{0}$. However, the equivalent stress anisotropy coefficient $\left(k^{\prime}\right)$ in equation (1) depends on both the stress anisotropy coefficient $(k)$ and the perforation angle $(\beta)$ which can be seen from equation (3). When the perforation length $(a)$ and the wellbore radius $(R)$ are constant, the variation of stress anisotropy coefficient results in the change of the equivalent stress anisotropy coefficient and consequently affects the value of $K_{\mathrm{I}-\sigma}$ which can be calculated using equation (1) and is shown in Figure 9. The intersection angle is clearly observed in Figure 9(a) when the perforation length $a=10 \mathrm{~mm} .\left|K_{\mathrm{I}-\sigma} / \sigma_{\mathrm{h}}\right|$ increases with the increment of stress anisotropy coefficient when $0^{\circ} \leq \beta \leq \beta_{0}$, while it shows the opposite pattern when $\beta_{0} \leq \beta \leq 90^{\circ}$, which is same as the corresponding feature shown in Figure 8(a). In summary, the reason for the appearance of the intersection point in Figure 8(a) is that the stress anisotropy coefficient results in an intersection point of $K_{\mathrm{I}-\sigma}$. The intersection point $\beta_{0}$ will gradually approximate zero with the increment of perforation length as shown in Figure 9(b). The value of $K_{\mathrm{I}-\sigma} / \sigma_{h}$ in the model without the wellbore (i.e., there is no wellbore in Figure 1(a)) and the perforation length of $(a+R)$ nearly equals that with wellbore when $a=300 \mathrm{~mm}$ and $k=3$, which indicates that the effect of the borehole radius on $K_{\mathrm{I}-\sigma}$ can be neglected when the value of $a / R$ is larger than a critical value.

Same as that in Figure 8(a), the critical water pressure for $a=100 \mathrm{~mm}$ is kept constant when the stress anisotropy coefficient $k=1.0$ as shown in Figure 8(c). Moreover, the 


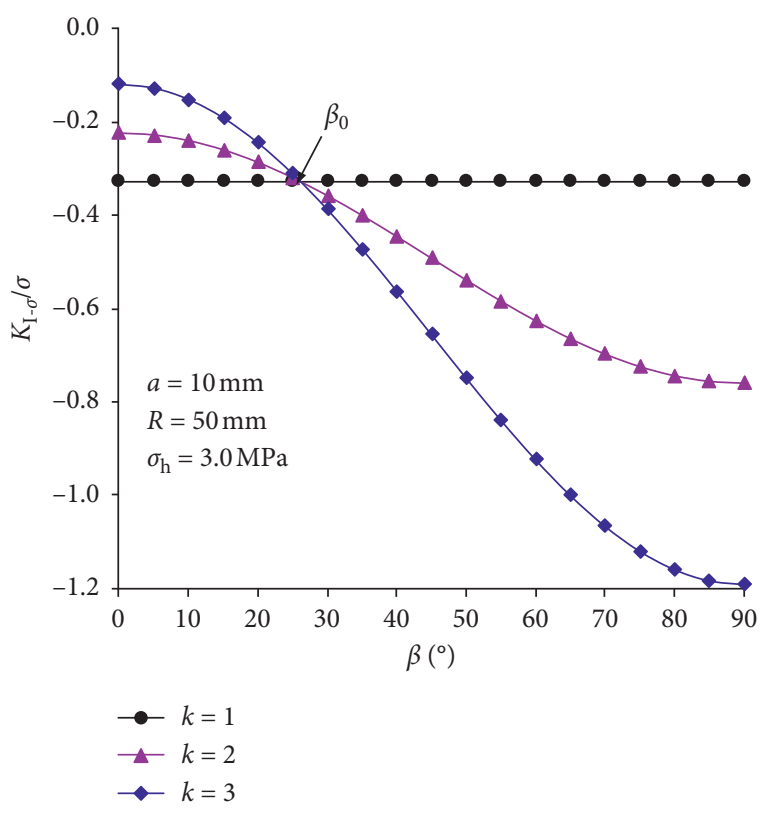

(a)

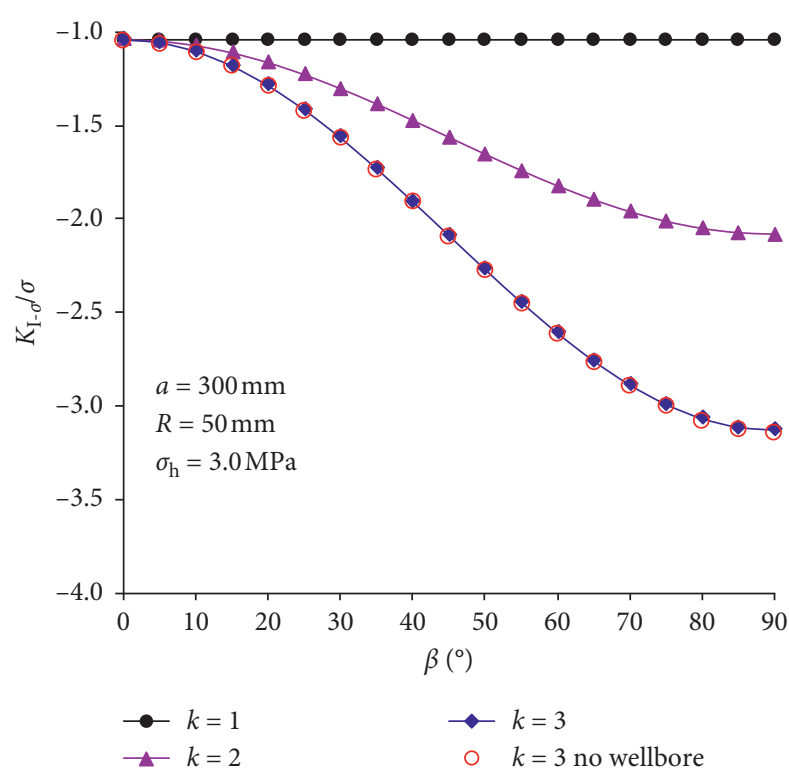

(b)

FIGURE 9: Influence of stress anisotropy coefficient on the mode-I stress intensity factor $K_{\mathrm{I}-\sigma}$.

critical water pressure increases with the increment of the perforation angle when the stress anisotropy coefficients are equal to 1.5 or 2.0. However, for the higher stress anisotropy coefficient such as $k=3$, the critical water pressure slightly decreases with the increment of the perforation angle, preceding the increase when the perforation angle exceeds a critical value.

Figures $8(b)-8(d)$ show the effect of the stress anisotropy coefficient on the critical initiation angle. With the increase of the perforation angle, the critical initiation angle deviates from the perforation direction, which increases at first, then maximize at $\beta=45^{\circ}$, and finally decreases. The curves of the critical initiation angle versus the perforation angle are symmetrical along $\beta=45^{\circ}$. When the perforation angle is parallel to the maximum or minimum horizontal stress directions, the critical initiation angle equals zero. The critical initiation angle increases as the stress anisotropy coefficient increases. When the perforation length is smaller than the wellbore radius, the critical initiation angle is also small even if the stress anisotropy coefficient is larger, which indicates that the fracture propagation direction is difficult to be changed away from the azimuth of the fracture. With the perforation length increasing, the critical initiation angle increases remarkably. Taking $k=2.5$ as an example, the maximum fracture initiation angle is $15.2947^{\circ}$ when $a=10 \mathrm{~mm}$, which, however, increases to $62.7121^{\circ}$ when $a=100 \mathrm{~mm}$. The critical initiation angle in the model with different stress anisotropy coefficients can be addressed as follows:

(1) At a given perforation angle, the critical initiation angle increases as the stress anisotropy coefficient increases. The reason is that the mode-II stress intensity factor $K_{\mathrm{II}}$ increases according to equations (4) and (5). According to equations (22) and (26), the effect of stress intensity factors $\left(K_{\mathrm{I}}\right.$ and $\left.K_{\mathrm{II}}\right)$ on the critical initiation angle $\left(\theta_{\mathrm{c}}\right)$ and equivalent stress intensity factor $\left(K_{\mathrm{eq}}\right)$ is shown in Figure 10 . Both the equivalent stress intensity factor and critical initiation angle increase as the value of $K_{\mathrm{II}} / K_{\mathrm{I}}$ increases. The critical initiation angle approaches $68.6^{\circ}$ when the ratio $K_{\mathrm{II}} / K_{\mathrm{I}}$ is greater than 5 and finally reaches $70.5^{\circ}$ if the ratio $K_{\mathrm{II}} / K_{\mathrm{I}}$ is sufficiently large. Therefore, when the perforation angle is close to the direction of the maximum or minimum horizontal stresses (both $\sigma_{\mathrm{h}}$ and $\sigma_{\mathrm{H}}$ ), the value of $K_{\mathrm{II}}$ is small, which means the value of $K_{\mathrm{II}} / K_{\mathrm{I}}$ is small and the fracture opening is the dominant fracture growth mode, the fracture does not twist much during its growth, and the critical initiation angle is almost zero. However, when perforation angle deviates much from the direction of the maximum or minimum horizontal stresses, the fracture propagation direction will turn and tend to align towards the orientation of the maximum horizontal stresses because the absolute value of the critical initiation angle increases gradually with the increase of the value of $K_{\mathrm{II}}$, as shown in Figure 10. As the value of $K_{\mathrm{II}} / K_{\mathrm{I}}$ becomes large enough, the shear sliding becomes the dominant mode of the fracture growth. Thus, according to the proposed theoretical model, for the model shown in Figure 1(a), the fracture will twist more during its growth under higher stress anisotropy coefficient conditions, which is same as the experimental results obtained by Ispas et al. [35]. This is what hydraulic fracturing engineers have been trying to alleviate or avoid.

(2) The fracture does not twist during its growth when the maximum horizontal stress is equal to the minimum horizontal stress (i.e., $k=1$ ) because the 


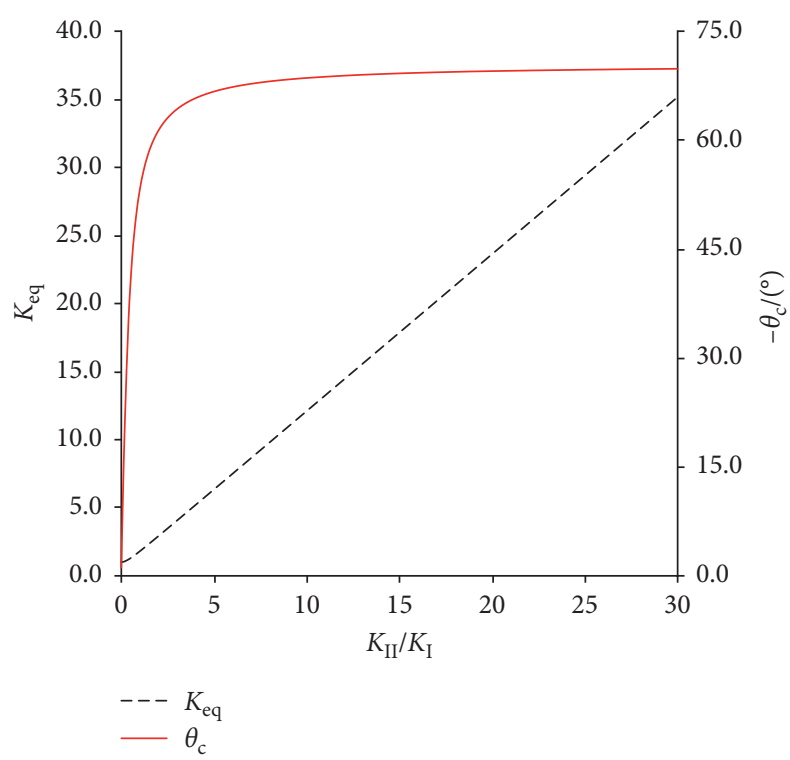

FIGURE 10: Effect of stress intensity factor on the critical initiation angle and equivalent stress intensity factor.

mode-II stress intensity factor is zero which can be observed from equations (4) and (5), and the shear sliding mode disappears under this condition. In other words, the fracture plane will not be twisted. This theoretical conclusion has also been proven by the experimental results [35].

(3) For the oil and gas reservoirs with higher stress anisotropy coefficient, to mitigate the fracture twist near the wellbore, it is recommended to reduce the inclination angle through adjusting the wellbore azimuth and/or perforation phasing. Thus, the proposed model and corresponding theoretical findings are significant to further understand the refracturing process in the hydraulic fracturing.

4.2. Effect of Borehole Radius. It can be seen from the theoretical model in Section 2 that the borehole radius affects both $K_{\mathrm{I}}$ and $K_{\mathrm{II}}$ and consequently affects the critical water pressure and critical initiation angle, which is shown in Figure 11. The perforation length is $a=20 \mathrm{~mm}$ in Figures 11(a) and 11(b) while $a=200 \mathrm{~mm}$ in Figures 11(c) and $11(\mathrm{~d})$. When $a=20 \mathrm{~mm}$, the critical water pressure drops significantly when the borehole radius increases from $50 \mathrm{~mm}$ to $100 \mathrm{~mm}$. Further increase of the borehole radius results in the continuous decrease of the critical water pressure although the decreasing rate significantly declines. When the perforation length is $a=200 \mathrm{~mm}$, the critical water pressure also decreases as the borehole radius increases. Figures 11(a) and 11(c) indicate that for a shorter perforation length (such as smaller than the wellbore radius), the effect of borehole radius on the critical water pressure is obvious when $R / a$ is smaller than 5 ; otherwise, it is unremarkable. The effect of borehole radius on the critical water pressure should not be neglected when the perforation angle is close to the direction of the maximum horizontal stress. However, if the perforation angle is close to the direction of the minimum horizontal stress, the effect of borehole radius on the critical water pressure can be neglected.

The effects of borehole radius on the critical initiation angle are illustrated in Figures 11(b) and 11(d), which depend on the perforation length. When the perforation length is smaller than the borehole radius, the critical initiation angle decreases as the borehole radius increases, in which the decreasing rate also slows down. However, when the perforation length is greater than the borehole radius, the critical initiation angle was almost not affected by the borehole radius, as shown in Figure 11(d).

4.3. Effect of Perforation Length. According to fracture mechanics, the increase of the perforation length increases the stress intensity factor, which therefore decreases the fracture initiation stress. As can be seen from Figure 11, for the borehole with two symmetrical radial perforations shown in Figure 1(a), the critical water pressure and critical initiation angle depend on the perforation length. Figure 12 shows the effect of the perforation length on the critical water pressure and critical initiation angle, where the borehole radius is constant. Figure 12 (a) indicates the perforation length significantly affects the critical water pressure, especially when $a<R$. The difference between the critical water pressures obtained for $a=20 \mathrm{~mm}$ and $50 \mathrm{~mm}$ is $0.7982 \mathrm{MPa}$ at $\beta=0^{\circ}$ and $1.6031 \mathrm{MPa}$ at $\beta=90^{\circ}$ although there is only $30 \mathrm{~mm}$ difference in the perforation length. However, with the increase of the perforation length, the difference between the critical water pressures obtained for the adjacent perforation lengths (such as $a=150 \mathrm{~mm}$ and $200 \mathrm{~mm}$ ) is not significant, which can also be observed in Figure 12(c). It shows that the critical water pressure significantly decreases at first as the perforation length increases and then linearly decreases as the perforation length increases. In other words, when $a<R$, the critical water pressure is very sensitive to the perforation length and nearly grows exponentially with the perforation length decreasing. Thus, the greater the perforation length, the easier the hydraulic fracture growth, which can be used in practical hydraulic fracture engineering. However, it is known that the preexisting fractures emanating from the horizontal well in petroleum engineering are created by perforating gun. Thus, the difficulties of the construction technology and the costs are to be considered when the perforating gun is used to produce the greater perforation length. Practical hydraulic fracturing engineering shows that there is a reasonable and economical perforation length for a specific borehole radius and a specific stress state.

Figures 12(b) and 12(d) indicate that the critical initiation angle initially increases exponentially as the perforation length increases when $a<R$ and then increases linearly when the perforation length is greater. This theoretical conclusion has also been demonstrated by the numerical simulation results of Sepehri et al. [4], who indicated that the longer the perforation length, the easier the reorientation from the initial perforation plane. In practical hydraulic 


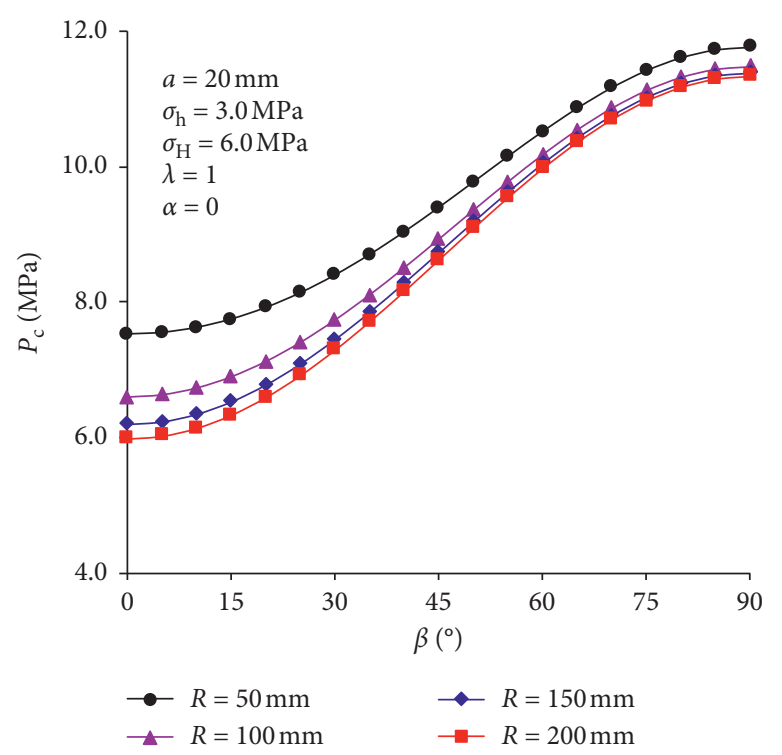

(a)

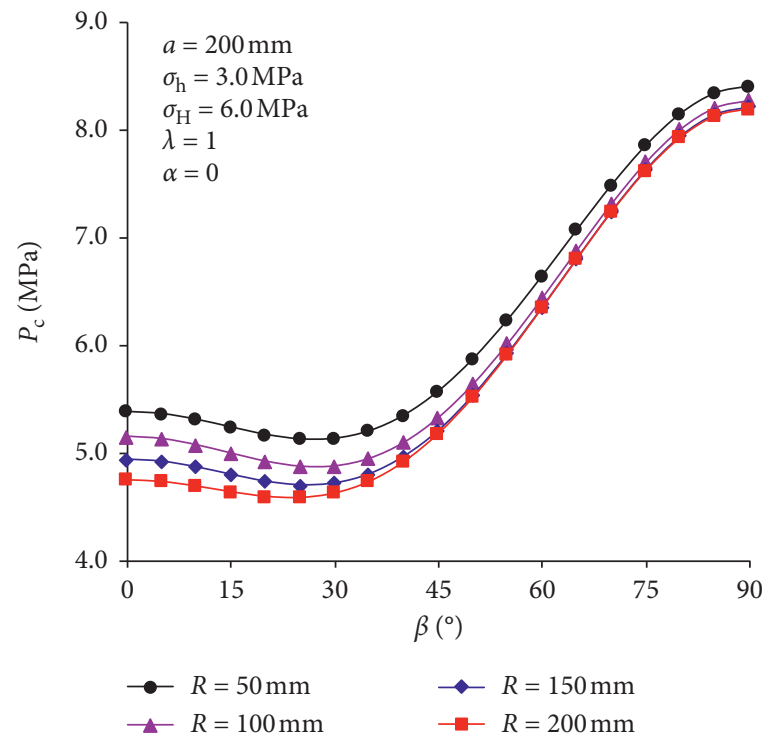

(c)

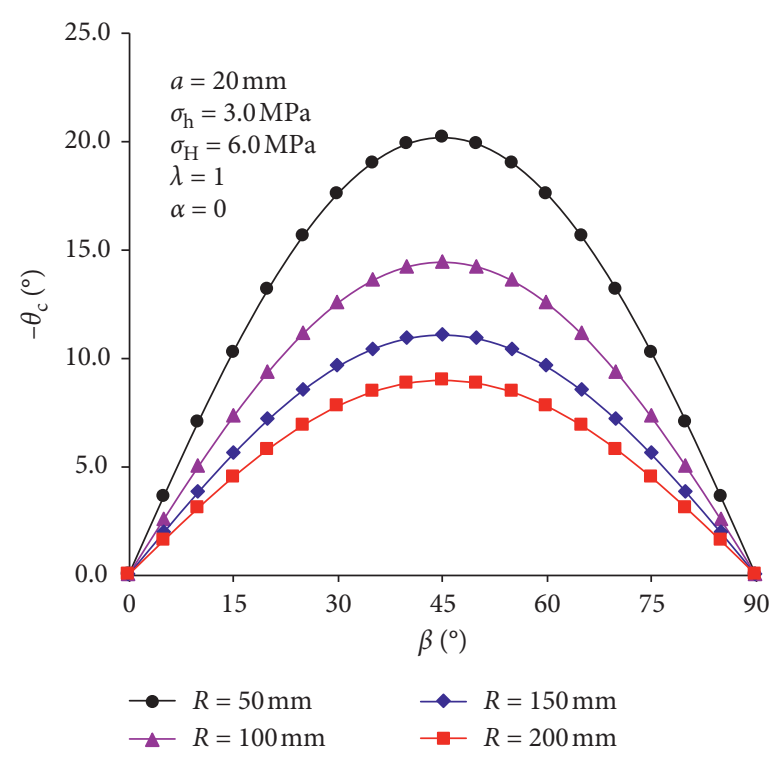

(b)

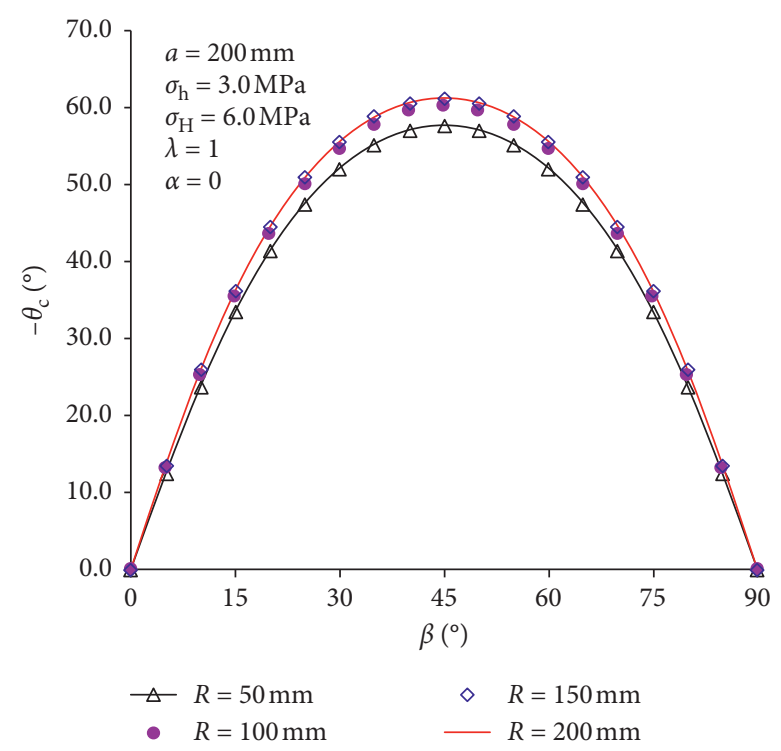

(d)

Figure 11: Effect of the borehole radius on the critical water pressure and critical initiation angle.

fracture engineering, the misalignment between the fracture initiation direction and the direction of the in situ stresses usually occurs because the well may be drilled in a direction that is not aligned with the principal stress directions or the perforations are not aligned with the preferred fracture direction. Therefore, as shown in Figure 12, the fracture initiation direction from a perforation or a natural fracture intersecting the wellbore may not align with the horizontal stress direction (except for the case of the perforation angle parallel to the orientation of the in situ principal stresses). In such cases, the hydraulic fracture will reorient its propagation direction as it grows away from the wellbore until its propagation direction is eventually parallel to the principal stress direction. An optimal perforation length for fracture propagation would require a minimal water injection pressure and would generate a fracture at an achievable fracture initiation pressure with minimal tortuosity [2]. It can be observed from Figure 12 that the greater perforation length decreases the critical water pressure but increases the twist of the fracture growth. Thus, to accurately quantify the critical water pressure in the hydraulic fracturing, the knowledge of an accurate perforation length is required, especially when the perforation length is short.

\subsection{Effect of Ratio between the Water Pressures in the Fracture} and the Borehole. Generally, the pressure in the fracture (i.e., so-called internal pressure) in impermeable rock caused by low viscous fluid is assumed to uniformly distribute along the fracture length and be equal to that in the borehole, 


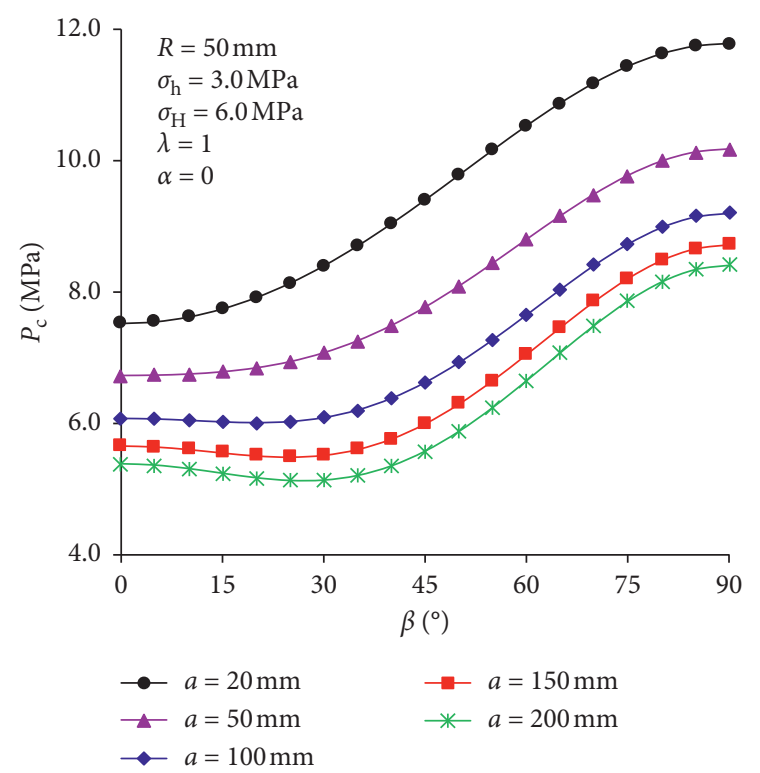

(a)

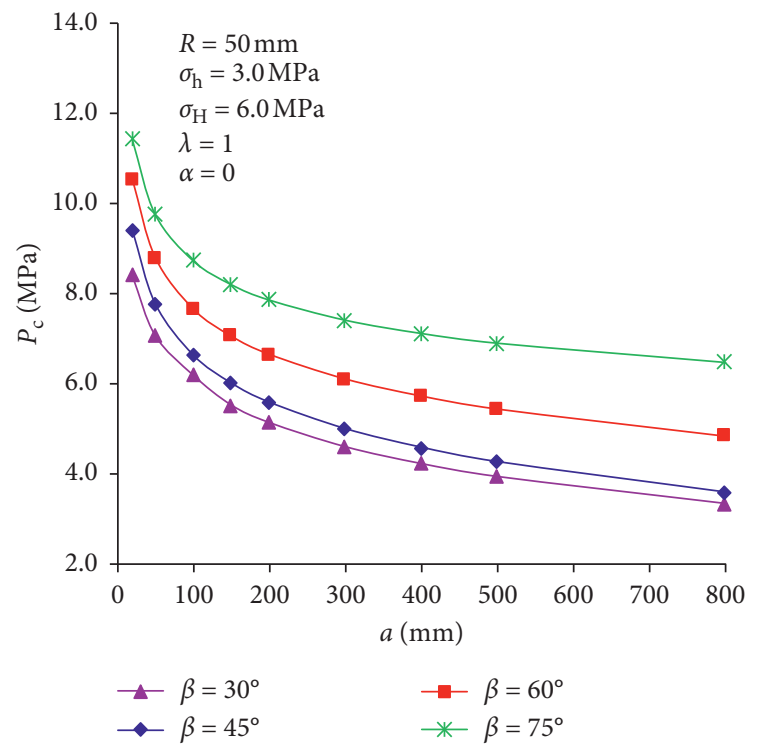

(c)

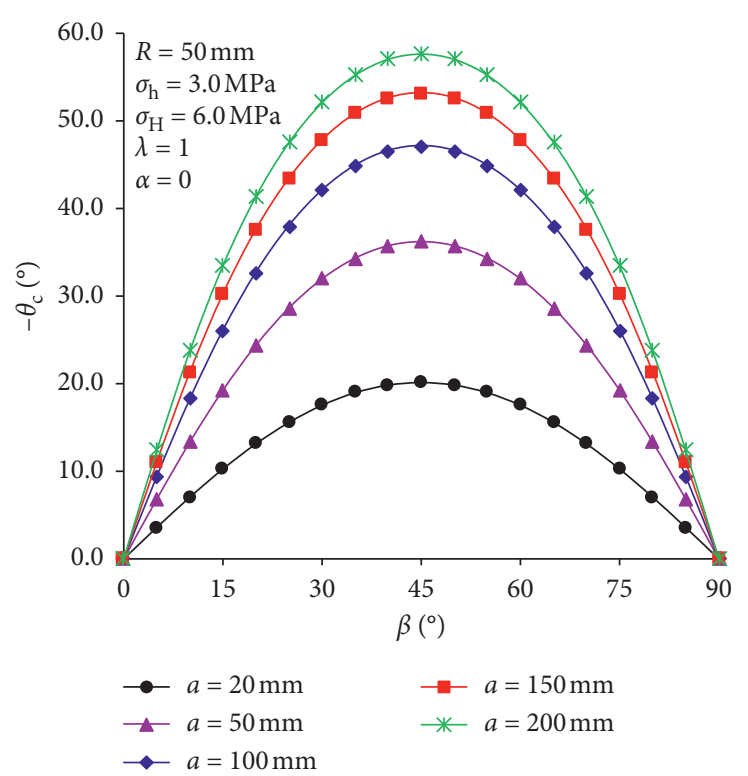

(b)

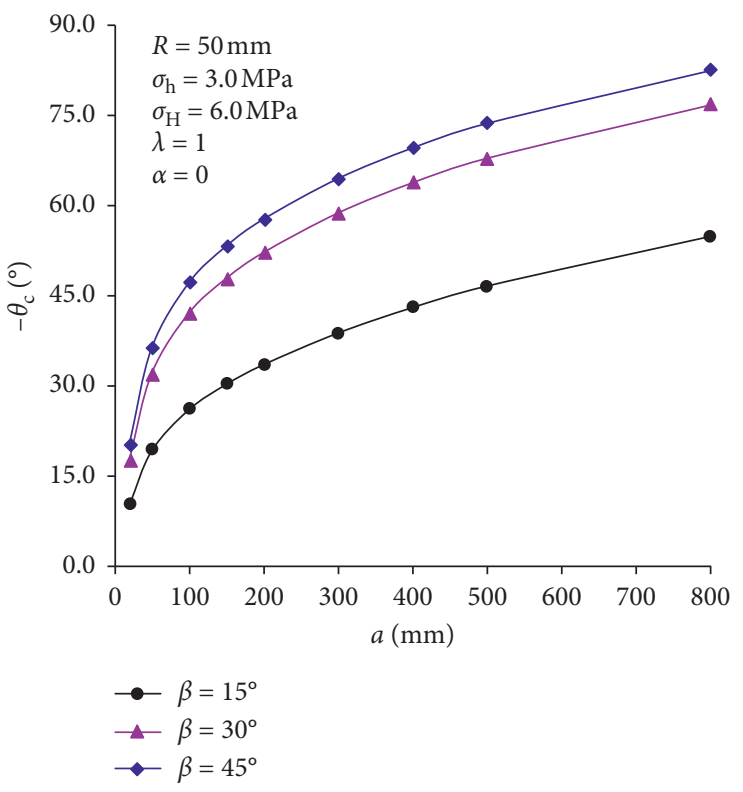

(d)

FIGURE 12: Effect of the perforation length on the critical water pressure and critical initiation angle.

i.e., $\lambda=1$. However, the viscous fluid and its permeation lead to that the internal pressure nonlinearly distributes along the fracture length in permeable rock. Jeffrey [36] assumed that the internal pressure at the heel of the preexisting fracture was equal to the borehole pressure, while that at the tip of the preexisting fracture was zero because of the existing fluid lag. Many other studies also discussed the existence of the zone without fluid at the tip of the advancing fracture [37-39].

The nonlinear distribution of the internal pressure in the fracture caused by the fluid viscosity and rock permeability can be considered in the proposed theoretical model, as proposed by Jeffrey [36]. The weight function method formulated in equations (10)-(14) can then be used to evaluate the mode-I stress intensity factor caused by the internal pressure and subsequently $K_{\mathrm{I}-\mathrm{P}}$ shown in equation (7) is replaced. However, in this study, the objective is not to derive an accurate decline function for the internal pressure inside preexisting fracture but to highlight the effect of the internal pressure on the critical water pressure and critical initiation angle. Therefore, the internal pressure is assumed to uniformly distribute along the fracture but its value is lower than that in the borehole by changing the parameter $\lambda$ shown in Figure $1(\mathrm{a})$. The corresponding results are shown in Figure 13. For the inclined perforation with a high internal pressure $(\lambda=1.0)$, the critical water pressure is lowest as shown in 


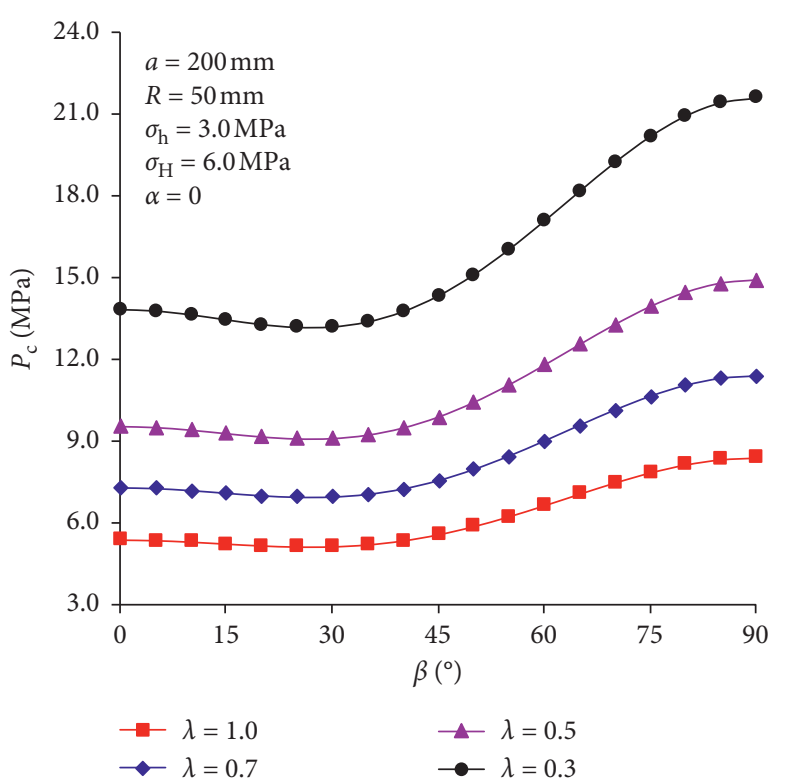

(a)

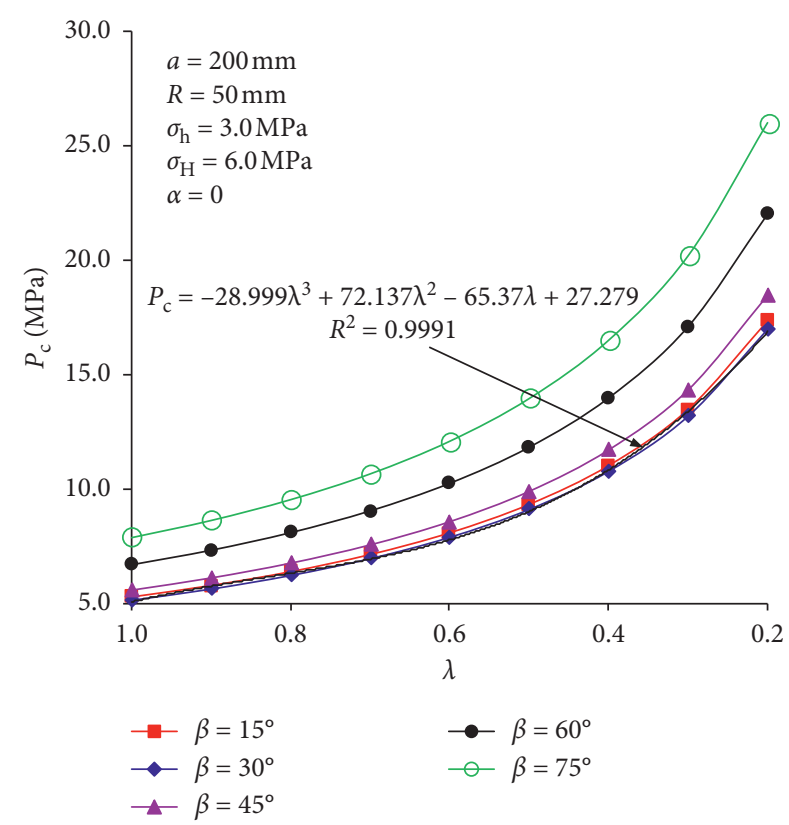

(b)

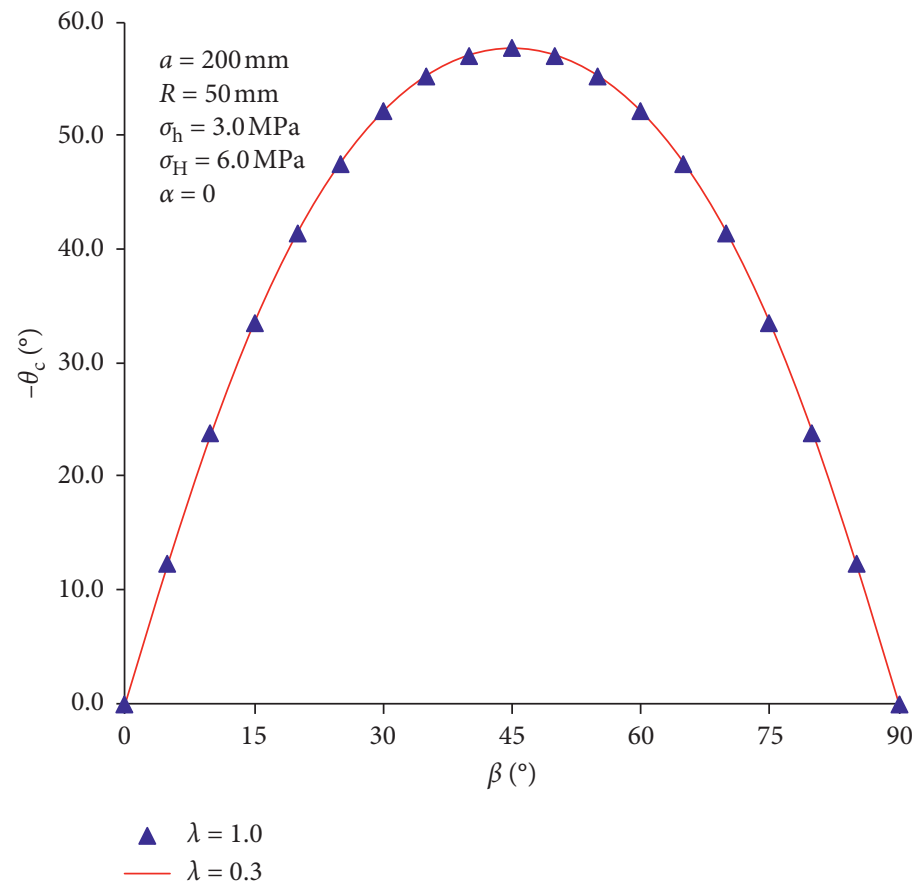

(c)

FIGURE 13: Effect of the ratio of water pressure in the fracture and the borehole on the critical water pressure and critical initiation angle.

Figure 13(a). With the decrease of the ratio $\lambda$, the critical water pressure increases rapidly according to a polynomial function of the parameter $\lambda$ such as that shown in Figure 13(b) when $\beta=15^{\circ}$.

However, the critical initiation angle is not affected by the ratio of the water pressures in the fracture and the borehole as shown in Figure 13(c). It is shown in Figure 10 that the reason for the twist of the fracture growth is the influence of the mode-II stress intensity factor. The change of $\lambda$ affects the mode-I stress intensity factor caused by the water injection pressure (i.e., $K_{\mathrm{I}-\mathrm{P}}$ ) in equation (7) but has no effect on $K_{\mathrm{II}}$ in equation (5). In other words, $K_{\mathrm{II}}$ is independent of $\lambda$; hence, the critical initiation angle does not change with the ratio $\lambda$ changing. The water injection pressure distribution in the fracture is an important parameter for the evaluation of the critical water pressure. The effect of the other factors such as the fluid permeability and viscosity, which may affect the pressure distribution in the fracture, should be further discussed in future studies. 
4.5. Effect of Biot's Coefficient. The elevated pore pressure distribution generates a poroelastic stress whose magnitude is proportional to the coefficient of effective stress during the elastic deformation of rocks [40]. This is usually referred to as Biot's coefficient, which has a value between 0 and 1 . Reported values of Biot's coefficient for crystalline rocks include 0.27 for charcoal granite [41]. Warpinski et al. [42] reported the variation of $\alpha$ with changes in stress and pore pressure for tight sandstone and chalk from 0.65 to 0.95 for westerly granite and 0.63 for stone mountain granites. These values indicate that Biot's coefficient is significantly greater than zero even for low porosity rocks.

Figure 14 shows the effect of Biot's coefficient $(\alpha)$ on the critical water pressure and critical initiation angle. It can be seen from Figure 14(a) that the critical water pressure decreases as Biot's coefficient increases, which is beneficial to the cost savings for the hydraulic fracturing engineering. According to equations (16) and (17), the value of $K_{\mathrm{I}-\alpha \mathrm{p}}$ increases as Biot's coefficient increases. Under a certain in situ stress situation, the borehole radius, the perforation length, and the mode-I and mode-II stress intensity factors in equations (1) and (5) are constant. Therefore, for constant mode-I fracture toughness $K_{\mathrm{IC}}, K_{\mathrm{I}}$ in equation (18) is also constant, which indicates the increase of $K_{\mathrm{I}-\alpha \mathrm{p}}$ decreases $K_{\mathrm{I}-P}$ and consequently reduces the critical water pressure. In other words, the critical water pressure decreases as the pore pressure increases. This result is very useful for the practical hydraulic fracturing engineering. For example, the pore pressure can be increased by allowing the fluid leak off into the formation or decreasing the flow rate to allow the fracturing fluid more time to leak off into the formation. The increase of the pore pressure then decreases the required the critical water pressure according to the proposed theoretical model and then helps cut the costs and enlarges the stimulated volume for the shale reservoirs. The theoretical results are consistent with the work of Gou et al. [43] and Bruno and Nakagawa [44], who showed that an increase of the pore pressure decreases the critical pressure required to initiate a fracture and reduce the width of the newly formed fracture. Figure 14(b) also suggests that the critical initiation angle is not affected by the pore pressure, which is same as the effect of the parameter $\lambda$ shown in Figure 13(c). The reason is that the change of $\alpha$ affects $K_{\mathrm{I}}$ but has no effect on $K_{\mathrm{II}}$.

\section{Effect of High-Pressure Water Injection}

In hydraulic fracturing engineering such as oil and gas exploitation and geothermal utilization, the stress state of the existing fracture changes with the changing injected water pressure. The high-pressure water injection may result in three kinds of states: (1) the fracture does not propagate because the injected water pressure is smaller than $P_{c},(2)$ the fracture growth occurs because of the suitable injected water pressure, and (3) the injected water pressure is too large, which leads to not only the fracture growth in the oil or gas reservoir but also the breakdown of other strata subsequently resulting in water leakage. The last state is usually observed in the practical hydraulic fracturing engineering, which is bad for the oil or gas exploration and even results in disasters. For example, in the deep geothermal development in Basel, Switzerland, due to the injected excessive water pressure, which induced earthquakes, the entire project was forced to be stopped. The injected different water pressures result in the different fracture initiation angles. For example, when the parameters $K_{\mathrm{IC}}=2.1 \mathrm{MPa} \cdot \mathrm{m}^{1 / 2}, a=100 \mathrm{~mm}$, $R=50 \mathrm{~mm}, \sigma_{\mathrm{h}}=3 \mathrm{MPa}, \sigma_{\mathrm{H}}=6 \mathrm{MPa}$, and $\lambda=1$, the pore pressure is neglected as shown in Figure 8(a). The minimum value and maximum value of critical water pressure are 6.0726 MPa and 9.2022 MPa, respectively. Therefore, if the injected water pressure is greater than $9.2022 \mathrm{MPa}$, the fracture will propagate in the whole range of the azimuth of the fracture, i.e., $0^{\circ} \sim 90^{\circ}$. Four injected water pressures are considered, i.e., $P=12,15,20$, and $25 \mathrm{MPa}$, and the corresponding results are shown in Figure 15. The results indicate that fracture initiation angle under high-pressure water injection loading condition is smaller than that under critical water pressure. At a given perforation angle, the higher the injected water pressure, the lower the fracture initiation angle. This is because the high-pressure water injection increases $K_{\mathrm{I}}$ while $K_{\mathrm{II}}$ is constant, which consequently decreases fracture initiation angle according to equation (22). In other words, the increase of $K_{\mathrm{I}}$ indicates the opening mode is overcoming the sliding mode. For $\beta=30^{\circ}$, fracture initiation angle is $42.0664^{\circ}$; however, it quickly drops to $16.9628^{\circ}$ when $P=12 \mathrm{MPa}$ and $6.9006^{\circ}$ when $P=25 \mathrm{MPa}$. When a horizontal well is fractured with a massive multistage hydraulic fracturing technology, the results obtained from this study indicate that the shape of the fracture near horizontal lateral is different at each stage, in which the fracture plane twists less at stage I than that at stage II. As a result, the increase of the injected water pressure will help reduce the fracture tortuosity near the wellbore and will then decrease the skin factor and increase the ultimate oil or gas recovery. However, too large injected pressures will not only increase the costs but also increase the risk of the pressure penetration into other strata inducing earthquakes. Thus, a suitable injected water pressure needs to be carefully estimated by the proposed theoretical model. Figure 15 also indicates that fracture initiation angle is more sensitive to the change of the pumping pressure for perforation angle near $45^{\circ}$, which needs additional attentions since the fracture may twist more in this region. Different from the condition of critical water pressure, the high-pressure water injection loading condition leads to the fracture initiation angle becoming nonsymmetric along the vertical line through $\beta=45^{\circ}$ in Figure 15, where the maximum value is about at $\beta=50^{\circ}$.

The fracture initiation angle may be different due to the variation of the injected water pressure, the in situ stresses, and the geometries of the fracture and the borehole. Figure 16 shows the effect of these parameters on the fracture initiation angle under high-pressure water injection loading condition (i.e., the injected water pressure is larger than the critical water pressure). All the results are calculated by assuming the injected water pressure to be $20 \mathrm{MPa}$.

Figures 16(a) and 16(b) illustrate the effect of the stress anisotropy coefficient on the fracture initiation angle under high-pressure water pressure loading condition, where the perforation lengths are different, i.e., long and short 


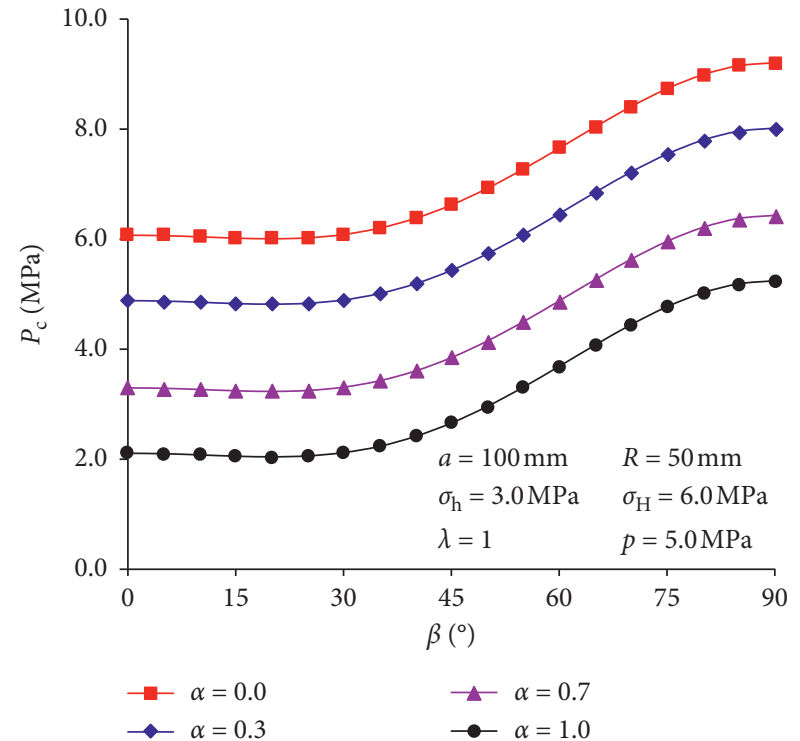

(a)

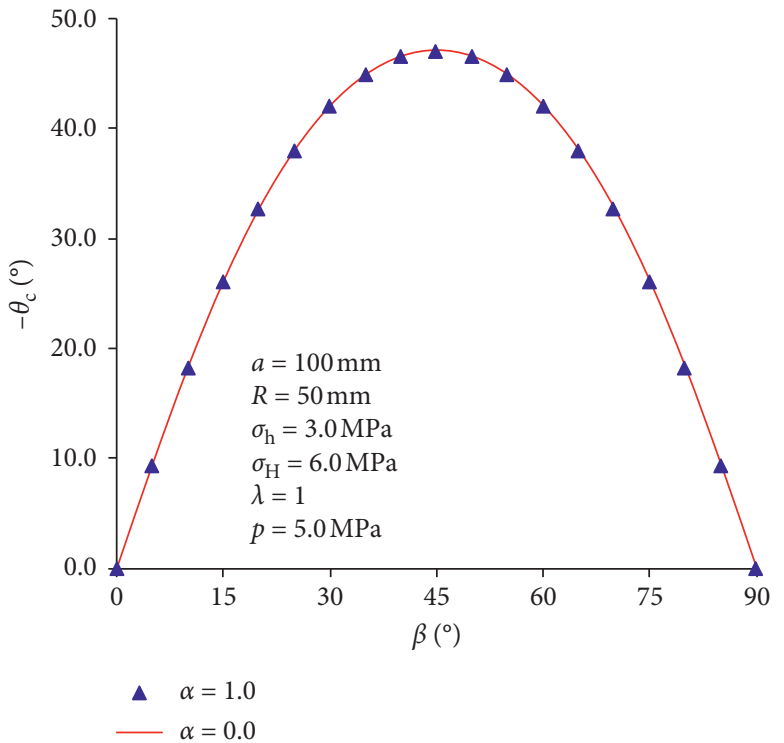

(b)

Figure 14: Effect of Biot's coefficient on the critical water pressure and critical initiation angle.

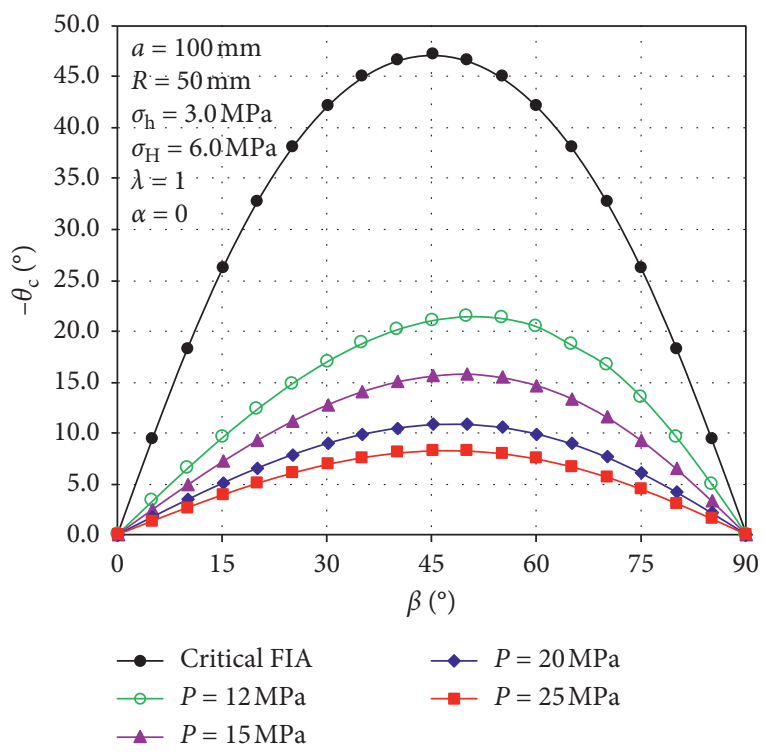

FIGURE 15: Influence of the high-pressure water injection on the fracture initiation angle.

perforations. The results indicate that the increase of the stress anisotropy coefficient increases the fracture initiation angle, for both short and long perforations. This is because the high stress anisotropy coefficient increases $K_{\mathrm{II}}$, indicating the sliding mode is enhanced. The results also suggest that the perforation length slightly affects the fracture initiation angle under the condition of the perforation length equal or larger than the borehole radius.

Both Figures 16(c) and 16(d) show the effect of the borehole radius on the fracture initiation angle under the high-pressure water injection loading condition with different perforation lengths. The results suggest that under the long perforation length (larger than the borehole radius), the fracture initiation angle is not significantly affected by the borehole radius. However, under the short perforation length, the fracture initiation angle decreases as the borehole radius increases. When the borehole radius is ten times larger than that of the perforation length, the maximum fracture initiation angle is only about $2.46^{\circ}$ at $\beta=50^{\circ}$. As the borehole radius increases further, the fracture initiation angle reduces to about $0^{\circ}$. It should be noted that with the growth of the fracture, the perforation length increases, resulting in the initially short fracture twists greatly during its growth such as that in Figure 16(d) and finally propagate along a constant angle such as that in Figure 16(c).

Figures 16(e) and 16(f) show the effect of perforation length on the fracture initiation angle under different borehole radius. The result shown in Figure 16(e) indicates that the perforation length does not affect the fracture initiation angle when the perforation length is longer than the borehole radius, i.e., $a \geq R$, which can also be seen in Figures 16(a) and 16(b). However, as shown in Figure 16(f), when the perforation length is shorter than the borehole radius, the increase of the perforation length increases the fracture initiation angle for the same perforation angle, such as that for $a=50 \mathrm{~mm}$ and $100 \mathrm{~mm}$. When the perforation length is larger than the wellbore radius, the fracture initiation angle does not change significantly with the increase of the perforation length, such as that for $a=150 \mathrm{~mm}$ and $200 \mathrm{~mm}$, which is same as the results shown in Figure 16(e). Therefore, if the perforation length is smaller than the wellbore radius, the fracture initiation angle increases with the growth of the fracture, while finally tends to be a constant value if the perforation length is much larger than the borehole radius.

Figure 16(g) shows that the fracture initiation angle increases with the decrease of $\lambda$, which suggests the higher 

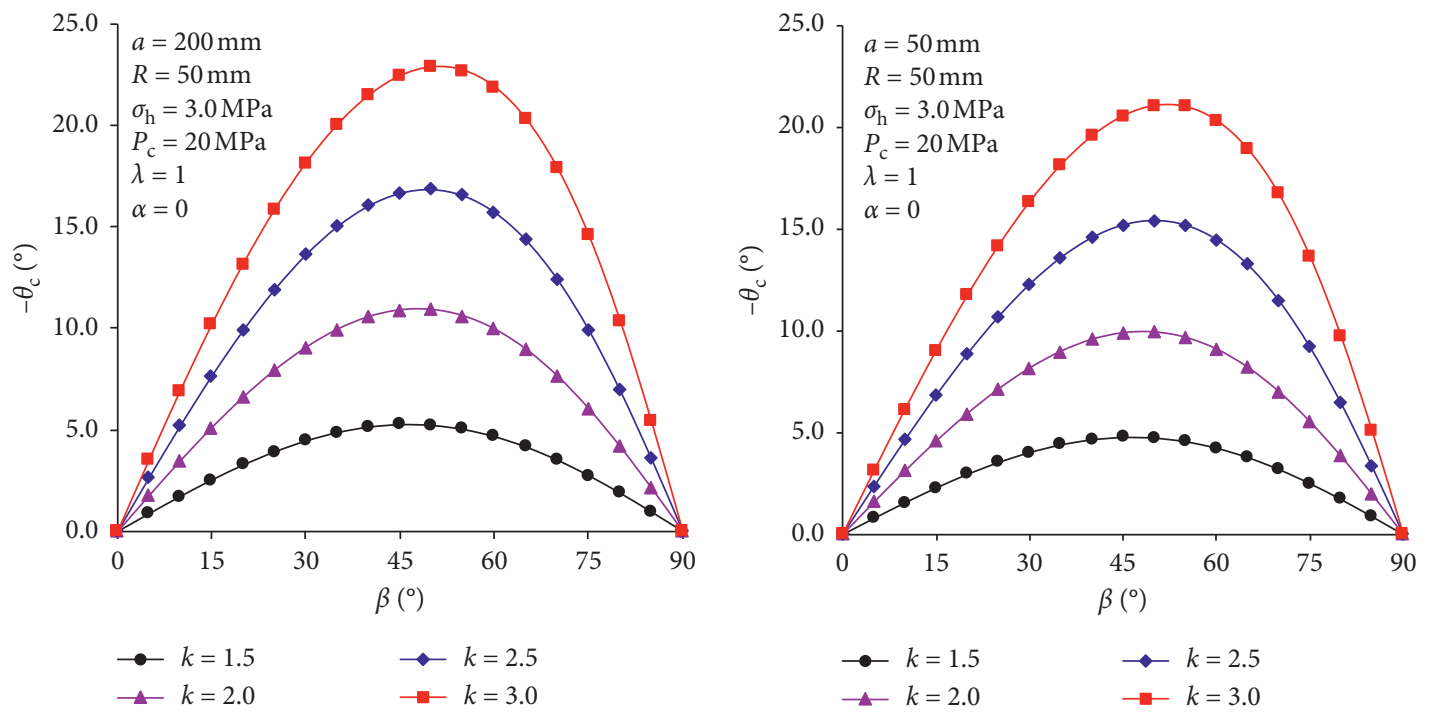

(a)
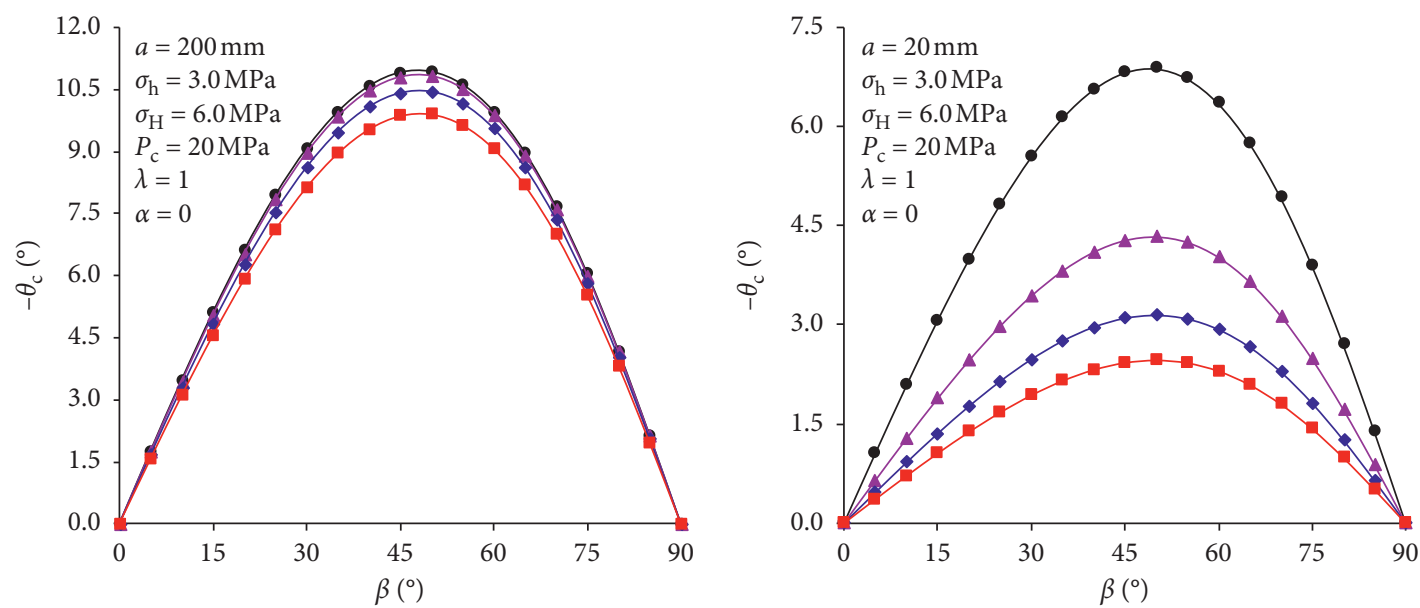

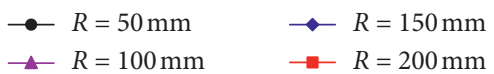

$\longrightarrow R=50 \mathrm{~mm} \quad \longrightarrow R=150 \mathrm{~mm}$

(c)

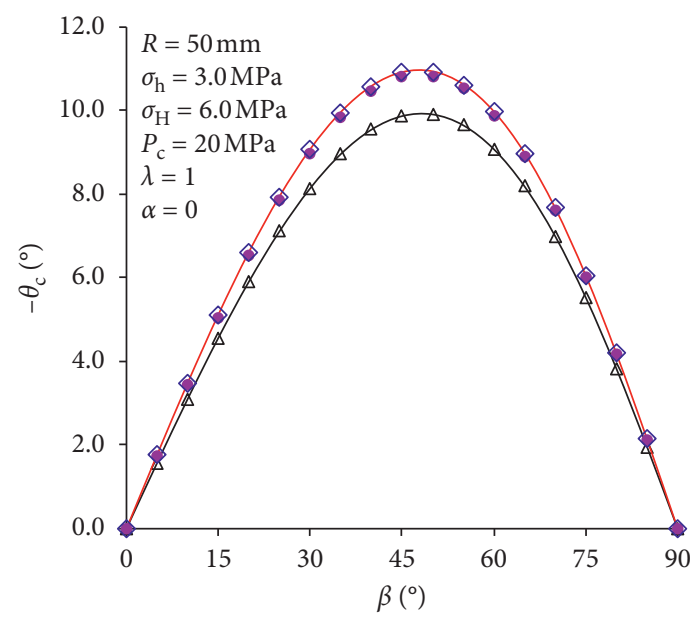

(d)

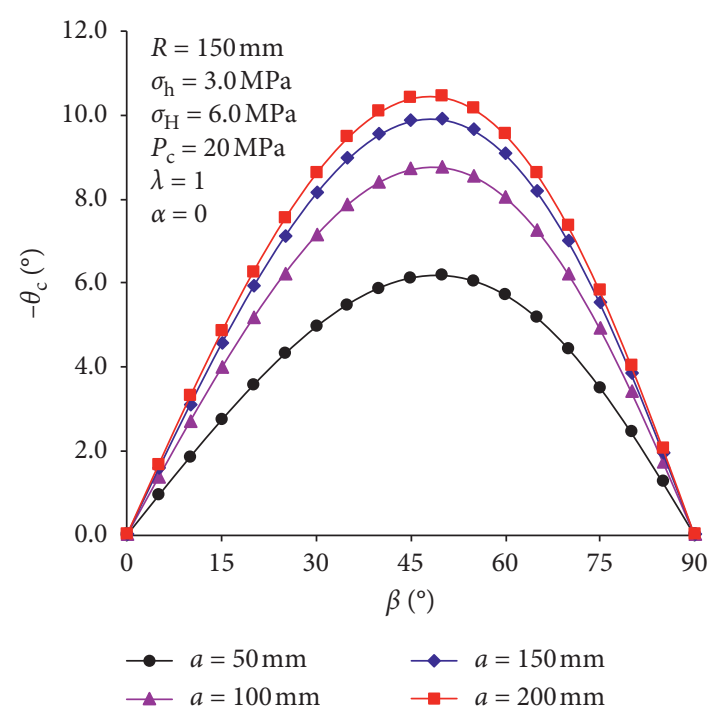

$\begin{aligned} \triangle a & =50 \mathrm{~mm} \quad \diamond \quad a=150 \mathrm{~mm} \\ \triangle a & =100 \mathrm{~mm} \quad \longrightarrow \quad a=200 \mathrm{~mm}\end{aligned}$

(e)

(f)

FIGURE 16: Continued. 


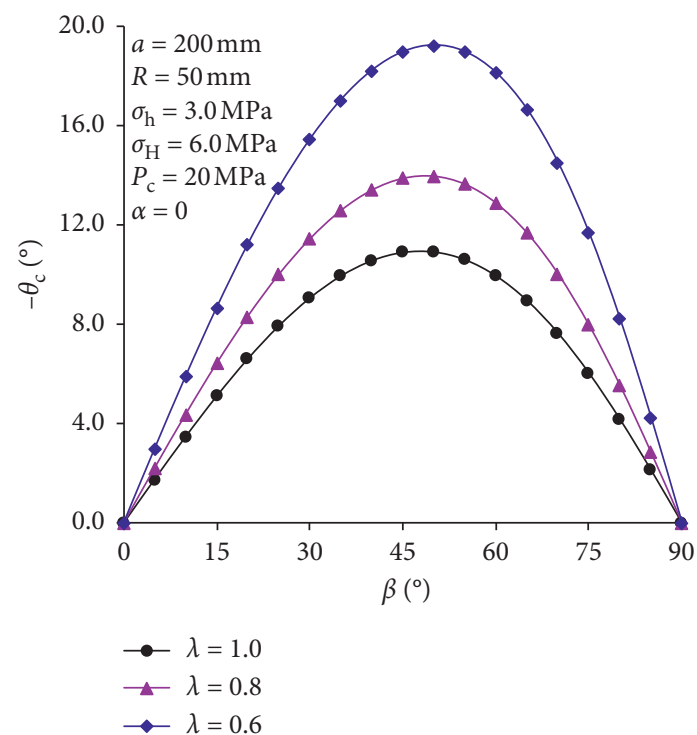

(g)

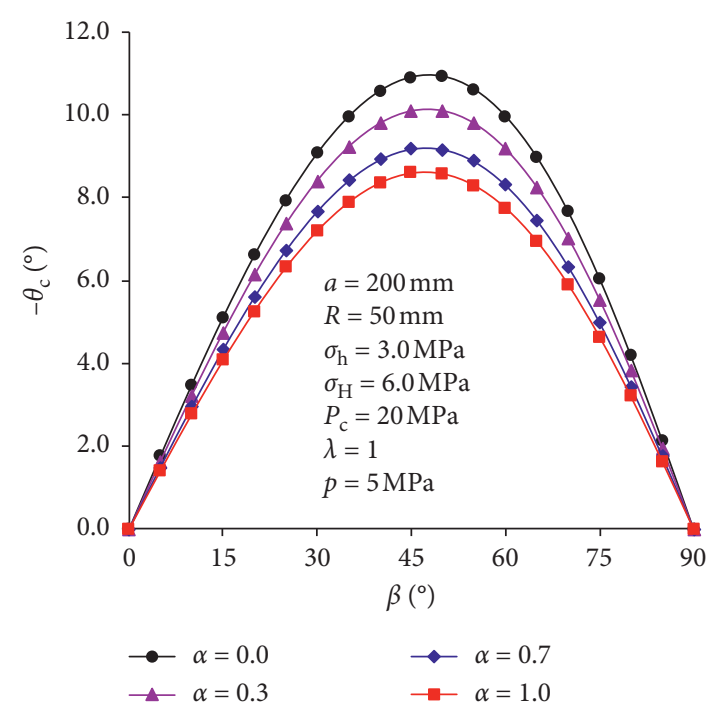

(h)

FIGURE 16: Effect of other factors on the fracture initiation angle under high-pressure water injection.

the fluid viscosity, the larger the fracture initiation angle. Figure $16(\mathrm{~h})$ indicates that at a given perforation angle, the higher Biot's coefficient, the lower the fracture initiation angle since $K_{\mathrm{I}}$ increases as Biot's coefficient increases according to equations (16) and (17). Biot's coefficient is an intrinsic property of rock and is not homogeneous [45]; this inhomogeneity leads to different fracture initiation angles under different stages of the hydraulic fracturing. Biot's coefficient is assumed to be a unit in the hydraulic fracturing simulators reported in many studies, which lead to an underestimation of the fracture initiation angle. An accurate laboratory measurement of Biot's coefficient is recommended to accurately predict the fracture geometry, especially for the hydraulic fracturing applied in shale gas and oil formations. The variation of Biot's coefficient changes the effective pore water pressure, i.e., $\alpha$ p, according to equations (16) and (17). In practical hydraulic fracturing engineering, Biot's coefficient as well as the pore pressure surrounding the fracture is a time dependent parameter, which suggests it is important to develop a fully coupled poroelastic fracture model to study the hydraulic fracture initiation behaviors. As mentioned in Section 4.5, the mechanical effect of increasing Biot's coefficient also can be regarded as keeping the value of Biot's coefficient constant but increasing the pore pressure. Therefore, for practical hydraulic fracturing engineering, the pore pressure can be increased by allowing fluid leak off through injecting the high water pressure or decreasing the flow rate to allow the fracturing fluid more time to leak into the formation, which avoids the fracture to twist during its growth and then benefit the design of the perforation angle.

\section{Conclusions}

An analytical model is proposed for investigating the hydraulic fracture initiation through a borehole with two symmetric radial perforations. The proposed model is implemented to predict the critical water pressure and fracture initiation angle for the hydraulic fracturing by considering the effect of the stress anisotropy coefficient, the borehole radius, the perforation angle and length, the injected water pressure, and the pore pressure in reservoir formation. According to the theoretical results, the following conclusions can be drawn:

(1) The proposed model addresses the effect of both the mode-I and mode-II stress intensity factors, i.e., $K_{\mathrm{I}}$ and $K_{\mathrm{II}}$ on the critical water pressure and fracture initiation angle, which is critical for studying the hydraulic fracturing under complex loading conditions. According to the theoretical model, the existence of the far-field equivalent shear stress is the main source of the twist of the fracture growth in hydraulic fracturing engineering. The critical water pressure and critical initiation angle derived from the theoretical model are compared against the results obtained from the experiments, and good agreement is found.

(2) The critical initiation angle increases as the stress anisotropy coefficient and perforation length increase. The trend of the critical water pressure depends on the perforation angle and the ratio of perforation length to that of the borehole radius $(a / R)$. The critical water pressure increases as the perforation angle increases when $a<R$ and $k \neq 1$, while the critical water pressure slightly decreases as the perforation angle increases at first and then increases when the perforation angle exceeds a critical value for $a>R$ and $k=3$. In addition, when $a<R$, the critical water pressure decreases with the increment of stress anisotropy coefficient for the perforation angle smaller than $\beta_{0}$, while just the 
opposite when the perforation angle is greater than $\beta_{0}$.

(3) The critical water pressure decreases as the borehole radius, the ratio between the water pressure in the fracture and the borehole $(\lambda)$, the perforation length, and Biot's ratio increase. The critical initiation angle is insensitive to the parameter $\lambda$ and Biot's coefficient. However, under high water pressure loading condition, the fracture initiation angle decreases as the parameter $\lambda$ and Biot's coefficient increase. In addition, the borehole radius has an important influence on the critical initiation angle for $a<R$, while the effect of the borehole radius on the critical initiation angle can be ignored for $a>R$.

The theoretical model developed in this study can be used to investigate the hydraulic fracture initiation through both vertical and horizontal wells. The obtained results help understand the characteristics of the hydraulic fracturing through the borehole with two symmetric radial cracks and provide guidelines for the drilling and hydraulic fracturing practice, but direct applications without any critical analysis may lead to risks due to the assumptions of linear elasticity, homogeneous material, symmetrical fracture, two dimension, etc. Moreover, it is valuable to implement this theoretical model in three-dimensional numerical simulator by incorporating the material heterogeneity.

\section{Data Availability}

The figure and table data used to support the findings of this study are included within the article.

\section{Conflicts of Interest}

The authors declare that there are no conflicts of interest regarding the publication of this paper.

\section{Acknowledgments}

This project was financially supported by the National Natural Science Foundation of China (51874065).

\section{References}

[1] A. Vengosh, N. Warner, R. Jackson, and T. Darrah, "The effects of shale gas exploration and hydraulic fracturing on the quality of water resources in the United States," Procedia Earth and Planetary Science, vol. 7, pp. 863-866, 2013.

[2] M. Chen, H. Jiang, G. Q. Zhang, and Y. Jin, “The experimental investigation of fracture propagation behavior and fracture geometry in hydraulic fracturing through oriented perforations," Petroleum Science and Technology, vol. 28, no. 13, pp. 1297-1306, 2010.

[3] M. Behnia, K. Goshtasbi, G. Zhang, and S. H. M. Yazdi, "Numerical modeling of hydraulic fracture propagation and reorientation," European Journal of Environmental and Civil Engineering, vol. 19, no. 2, pp. 152-167, 2015.

[4] J. Sepehri, M. Y. Soliman, and S. M. Morse, "Application of extended finite element method to simulate hydraulic fracture propagation from oriented perforations," in Proceedings of the
SPE Hydraulic Fracturing Technology Conference, Society of Petroleum Engineers, The Woodlands, TX, USA, 2015.

[5] H. Zhu, J. Deng, X. Jin, L. Hu, and B. Luo, "Hydraulic fracture initiation and propagation from wellbore with oriented perforation," Rock Mechanics and Rock Engineering, vol. 48, no. 2, pp. 585-601, 2014.

[6] Z. Dong, S. Tang, P. G. Ranjith, and Y. Lang, "A theoretical model for hydraulic fracturing through a single radial perforation emanating from a borehole," Engineering Fracture Mechanics, vol. 196, pp. 28-42, 2018.

[7] S. Tang, "The effects of water on the strength of black sandstone in a brittle regime," Engineering Geology, vol. 239, pp. 167-178, 2018.

[8] S. B. Tang, C. Y. Yu, M. J. Heap, P. Z. Chen, and Y. G. Ren, "The influence of water saturation on the short- and longterm mechanical behavior of red sandstone," Rock Mechanics and Rock Engineering, vol. 51, no. 9, pp. 2669-2687, 2018.

[9] X. Jin, S. Shah, J.-C. Roegiers, and J. McLennan, "Weight function of stress intensity factor for symmetrical radial cracks emanating from hollow cylinder," Engineering Fracture Mechanics, vol. 159, pp. 144-154, 2016.

[10] C. Y. Dong and C. J. De Pater, "Numerical implementation of displacement discontinuity method and its application in hydraulic fracturing," Computer Methods in Applied Mechanics and Engineering, vol. 191, no. 8-10, pp. 745-760, 2001.

[11] M. Behnia, K. Goshtasbi, M. F. Marji, and A. Golshani, "Numerical simulation of crack propagation in layered formations," Arabian Journal of Geosciences, vol. 7, no. 7, pp. 2729-2737, 2014.

[12] B. Sobhaniaragh, V. P. Nguyen, W. J. Mansur, and F. C. Peters, "Pore pressure and stress coupling in closelyspaced hydraulic fracturing designs on adjacent horizontal wellbores," European Journal of Mechanics-A/Solids, vol. 67, pp. 18-33, 2018.

[13] B. G. da Silva and H. Einstein, "Physical processes involved in the laboratory hydraulic fracturing of granite: visual observations and interpretation," Engineering Fracture Mechanics, vol. 191, pp. 125-142, 2018.

[14] W. Cheng, G. Jiang, H. Tian, and Q. Zhu, "Numerical investigations of the fracture geometry and fluid distribution of multistage consecutive and alternative fracturing in a horizontal well," Computers and Geotechnics, vol. 92, pp. 41-56, 2017.

[15] X. Zhang, R. G. Jeffrey, A. P. Bunger, and M. Thiercelin, "Initiation and growth of a hydraulic fracture from a circular wellbore," International Journal of Rock Mechanics and Mining Sciences, vol. 48, no. 6, pp. 984-995, 2011.

[16] V. Sesetty and A. Ghassemi, "Effect of rock anisotropy on wellbore stresses and hydraulic fracture propagation," International Journal of Rock Mechanics and Mining Sciences, vol. 112, pp. 369-384, 2018.

[17] R. Prabhakaran, H. De Pater, and J. Shaoul, "Pore pressure effects on fracture net pressure and hydraulic fracture containment: insights from an empirical and simulation approach," Journal of Petroleum Science and Engineering, vol. 157, pp. 724-736, 2017.

[18] H. Shimizu, S. Murata, and T. Ishida, "The distinct element analysis for hydraulic fracturing in hard rock considering fluid viscosity and particle size distribution," International Journal of Rock Mechanics and Mining Sciences, vol. 48, no. 5, pp. 712-727, 2011.

[19] A. Gholami, M. A. Aghighi, and S. S. Rahman, "Effect of nonuniform pore pressure fields on hydraulic fracture 
propagation," Journal of Petroleum Science and Engineering, vol. 159, pp. 889-902, 2017.

[20] J. C. Newman, An Improved Method of Collocation for the Stress Analysis of Cracked Plates with Various Shaped Boundaries, National Aeronautics and Space Administration, Washington, DC, USA, 1971.

[21] B. M. Liaw and M. Kamel, "Stress intensity factors for cracks emanating from a curvilinear hole in an anisotropic plane under arbitrary loadings," Engineering Fracture Mechanics, vol. 36, no. 5, pp. 669-681, 1990.

[22] Y. C. Hsu, "The infinite sheet with two radial cracks from cylindrical hole under inclined tension or in-plane shear," International Journal of Fracture, vol. 13, no. 6, pp. 839-845, 1977.

[23] H. Tada, P. C. Paris, and G. R. Irwin, The Stress Analysis of Cracks, ASME Press, New York, NY, USA, 2000.

[24] ANSYS Mechanical Theory Reference: Release 15.0, Canonsburg, PA, USA, 2014.

[25] B. Zhang, X. Li, Z. Zhang, Y. Wu, Y. Wu, and Y. Wang, "Numerical investigation of influence of in-situ stress ratio, injection rate and fluid viscosity on hydraulic fracture propagation using a distinct element approach," Energies, vol. 9, no. 3, p. 140, 2016.

[26] W. Xu, X. R. Wu, Y. Yu, and Z. H. Li, "A weight function method for mixed modes hole-edge cracks," Fatigue \& Fracture of Engineering Materials \& Structures, vol. 41, no. 1, pp. 223-234, 2018.

[27] F. Erdogan and G. C. Sih, "On the crack extension in plates under plane loading and transverse shear," Journal of Basic Engineering, vol. 85, no. 4, pp. 519-525, 1963.

[28] S. B. Tang, "The effect of T-stress on the fracture of brittle rock under compression," International Journal of Rock Mechanics and Mining Sciences, vol. 79, pp. 86-98, 2015.

[29] S. G. Mogilevskaya, L. Rothenburg, and M. B. Dusseault, "Growth of pressure-induced fractures in the vicinity of a wellbore," International Journal of Fracture, vol. 104, no. 4, pp. 23-30, 2000.

[30] B. Lecampion and J. Desroches, "Simultaneous initiation and growth of multiple radial hydraulic fractures from a horizontal wellbore," Journal of the Mechanics and Physics of Solids, vol. 82, pp. 235-258, 2015.

[31] J. Q. Bao, E. Fathi, and S. Ameri, "A coupled finite element method for the numerical simulation of hydraulic fracturing with a condensation technique," Engineering Fracture Mechanics, vol. 131, pp. 269-281, 2014.

[32] D. I. Garagash, "Propagation of a plane-strain hydraulic fracture with a fluid lag: early-time solution," International Journal of Solids and Structures, vol. 43, no. 18-19, pp. 5811-5835, 2006.

[33] X. Jin, An Integrated Geomechanics and Petrophysics Study of Hydraulic Fracturing in Naturally Fractured Reservoirs, University of Oklahoma, Norman, OK, USA, 2014.

[34] Z. Cui, D. Liu, G. An, and M. Zhou, "Research progress in mode-I fracture toughness testing methods for rocks," Journal of Test and Measurement Technology, vol. 23, no. 3, pp. 189-196, 2007.

[35] I. Ispas, R. Eve, R. Hickman, R. G. Keck, S. M. Willson, and K. E. Olson, "Laboratory testing and numerical modelling of fracture propagation from deviated wells in poorly consolidated formations," in Proceedings of the SPE Annual Technical Conference and Exhibition, Society of Petroleum Engineers, San Antonio, TX, USA, October 2012.

[36] R. G. Jeffrey, "The combined effect of fluid lag and fracture toughness on hydraulic fracture propagation," in Proceedings of the Joint Rocky Mountain Regional/Low Permeability Reservoirs Symposium, pp. 269-276, Society of Petroleum Engineers, Denver, CO, USA, 1989.

[37] A. P. Bunger and E. Detournay, "Asymptotic solution for a penny-shaped near-surface hydraulic fracture," Engineering Fracture Mechanics, vol. 72, no. 16, pp. 2468-2486, 2005.

[38] E. Gordeliy and E. Detournay, "A fixed grid algorithm for simulating the propagation of a shallow hydraulic fracture with a fluid lag," International Journal for Numerical and Analytical Methods in Geomechanics, vol. 35, no. 5, pp. 602-629, 2011.

[39] B. Lecampion and E. Detournay, "An implicit algorithm for the propagation of a hydraulic fracture with a fluid lag," Computer Methods in Applied Mechanics and Engineering, vol. 196, no. 49-52, pp. 4863-4880, 2007.

[40] T. Ito, K. Evans, K. Kawai, and K. Hayashi, "Hydraulic fracture reopening pressure and the estimation of maximum horizontal stress," International Journal of Rock Mechanics and Mining Sciences, vol. 36, no. 6, pp. 811-826, 1999.

[41] E. Detournay and A. H. D. Cheng, "Fundamentals of poroelasticity," in Comprehensive Rock Engineering, Pergamon Press, Oxford, UK, 1993.

[42] N. R. Warpinski and L. W. Teufel, "Determination of the effective-stress law for permeability and deformation in lowpermeability rocks," SPE Formation Evaluation, vol. 7, no. 2, pp. 123-131, 1992.

[43] F. Guo, N. R. Morgenstern, and J. D. Scott, "Interpretation of hydraulic fracturing breakdown pressure," International Journal of Rock Mechanics and Mining Sciences \& Geomechanics Abstracts, vol. 30, no. 6, pp. 617-626, 1993.

[44] M. S. Bruno and F. M. Nakagawa, "Pore pressure influence on tensile fracture propagation in sedimentary rock," International Journal of Rock Mechanics and Mining Sciences \& Geomechanics Abstracts, vol. 28, no. 4, pp. 261-273, 1991.

[45] S. Saurabh and S. Harpalani, "The effective stress law for stress-sensitive transversely isotropic rocks," International Journal of Rock Mechanics and Mining Sciences, vol. 101, pp. 69-77, 2018. 


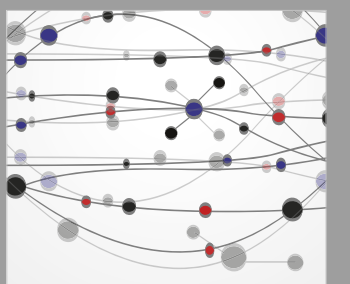

The Scientific World Journal
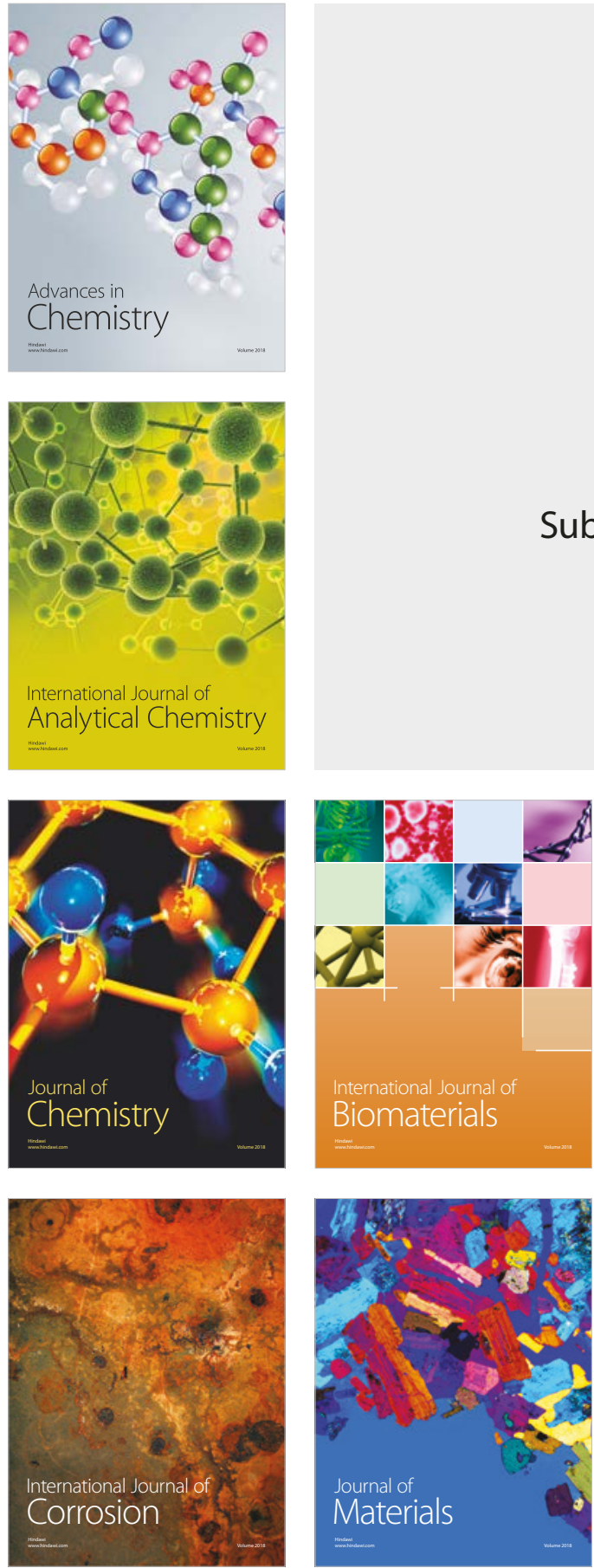

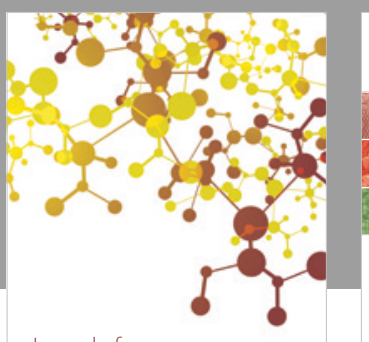

Journal of

Applied Chemistry
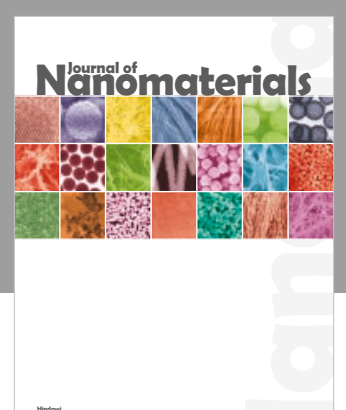

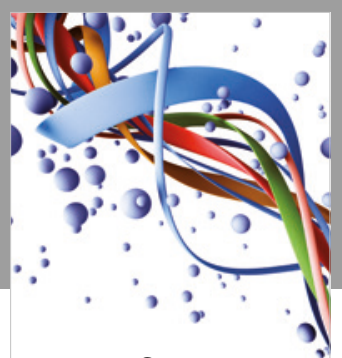

Scientifica

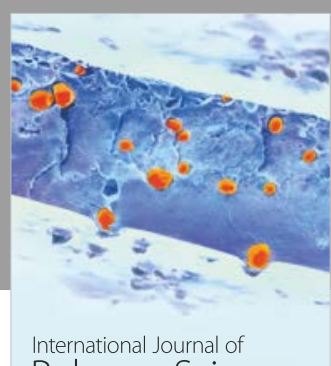

Polymer Science

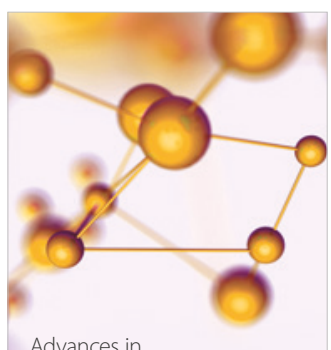

Physical Chemistry
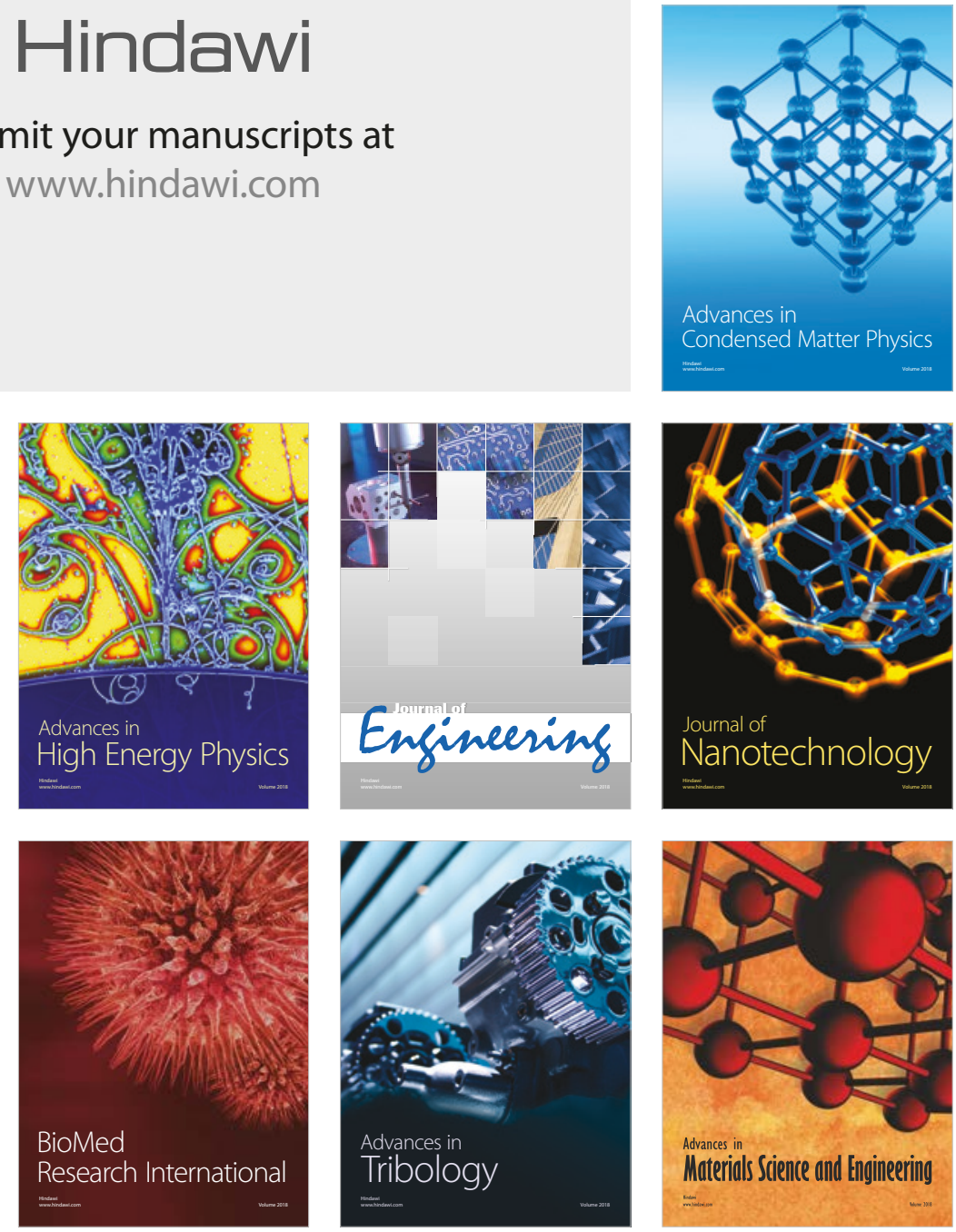